\title{
Investigation of Tunable Diode Spectroscopy for Monitoring Gases in Geothermal Plants
}

\author{
J.K. Partin
}

August 2006

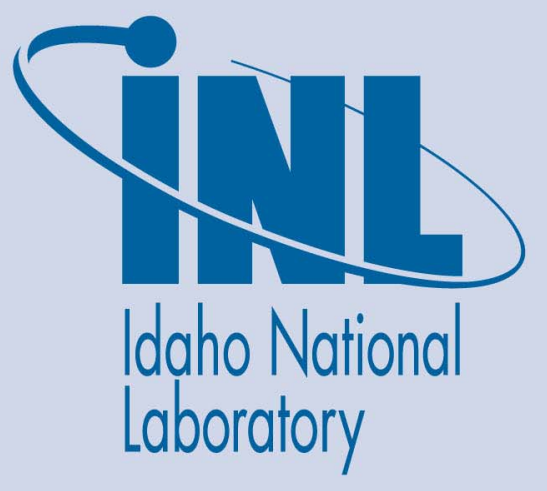

The INL is a U.S. Department of Energy National Laboratory operated by Battelle Energy Alliance 
INL/EXT-06-11811

\title{
Investigation of Tunable Diode Spectroscopy for Monitoring Gases in Geothermal Plants
}

\author{
J.K. Partin
}

August 2006

Idaho National Laboratory

Idaho Falls, Idaho 83415

Prepared for the

U.S. Department of Energy

Assistant Secretary for Energy Efficiency and Renewable Energy Under DOE Idaho Operations Office

Contract DE-AC07-05ID14517 


\begin{abstract}
The results of an investigation directed at the development of instrumenttation for the real-time monitoring of gases, such as hydrogen sulfide $\left(\mathrm{H}_{2} \mathrm{~S}\right)$ and chloride $(\mathrm{HCl})$, in geothermal process streams are described. The geothermal power industry has an interest in the development of new low maintenance techniques since improved capabilities could lead to considerable cost savings through the optimization of various gas abatement processes.

Tunable diode laser spectroscopy was identified as a candidate technology for this application and a commercial instrument was specified and procured for testing. The measurement principle involved the use of solid state diode lasers and frequency modulation techniques. The gallium arsenide diode lasers employed emit light in the 0.7 to 2.0 micron region of the electromagnetic spectrum. This region contains the overtone and combination absorption bands of a number of species of industrial interest, including $\mathrm{H}_{2} \mathrm{~S}$ and $\mathrm{HCl}$. A particular device can be tuned over a small range to match the absorption line by changing its applied temperature and current. The diode current can also be sinusoidally modulated in frequency as it is tuned across the line. This modulation allows measurements to be conducted at frequencies where the laser intensity noise is minimal; and therefore, very high signal-to-noise measurements are possible.

The feasibility of using this technology in various types of geothermal process streams has been explored. The results of laboratory and field studies are presented along with new advances in laser technology that could allow more sensitive and selective measurements to be performed.
\end{abstract}




\section{ACKNOWLEDGMENTS}

The author would like to thank the operations personnel at the Northern California Power Agency; and in particular, Managers Murray Grande and Steve Miller, for their support of the $\mathrm{H}_{2} \mathrm{~S}$ field trials. She would also like to thank President Paul Hirtz, Russell Kunzman, and the staff at Thermochem, Inc. for their help with the $\mathrm{HCl}$ steam experiments.

The contributions of her colleagues, Charles Jeffery, Greg Lancaster, and Greg Mines are also acknowledged. Charles Jeffery assisted with the laboratory experiments. Greg Lancaster participated in the untreated vent gas field experiment. Greg Mines transported and installed the systems at the field sites; and in addition, provided valuable insight into geothermal operations.

This work was supported by the U. S. Department of Energy, Assistant Secretary for Energy Efficiency and Renewable Energy, under DOE-NE Idaho Operations Contract DE-AC07-05ID14517. 


\section{CONTENTS}

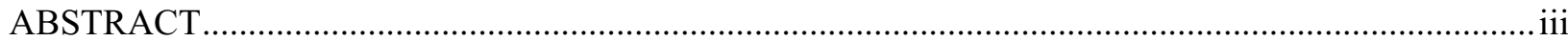

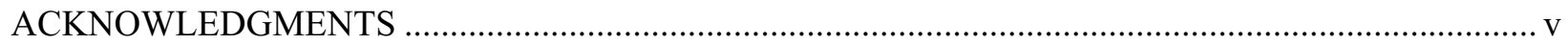

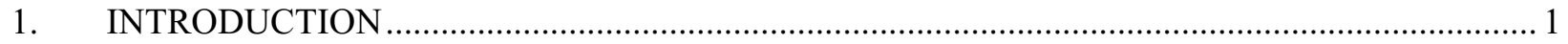

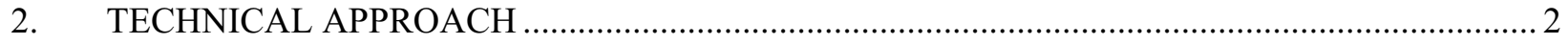

2.1 Tunable Diode Laser Absorption Spectroscopy …............................................................. 2

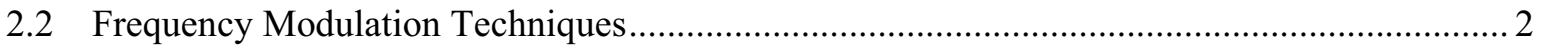

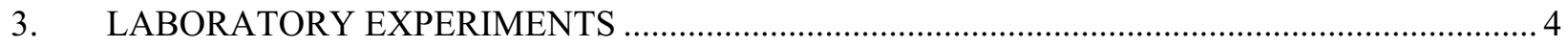

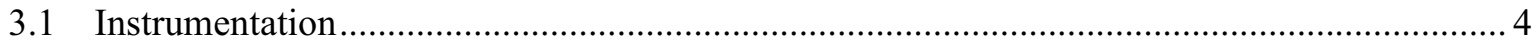

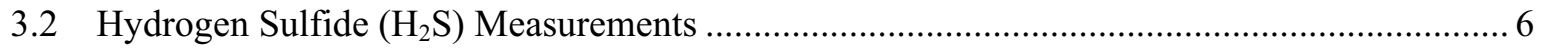

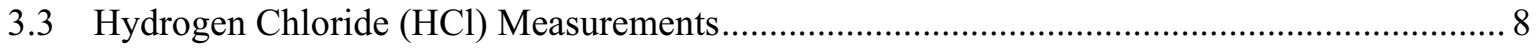

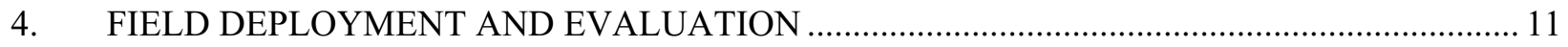

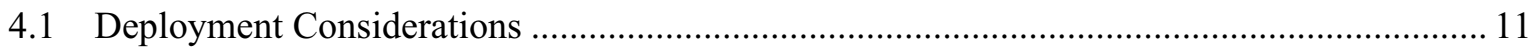

4.2 On-line Measurement of $\mathrm{H}_{2} \mathrm{~S}$ in the Untreated Vent Gas Stream....................................... 12

4.3 On-line Measurement of $\mathrm{H}_{2} \mathrm{~S}$ in the Treated Vent Gas Stream .......................................... 16

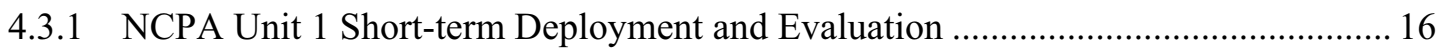

4.3.2 NCPA Unit 2 Extended Deployment and Evaluation........................................... 20

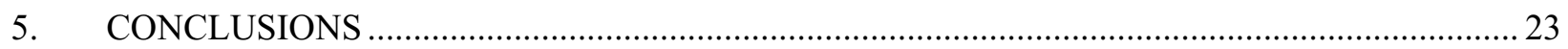

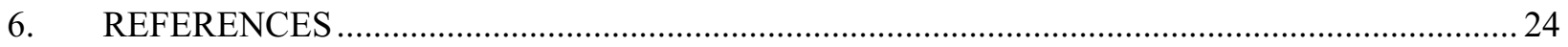

\section{FIGURES}

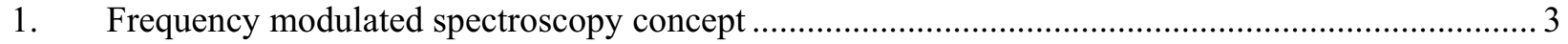

2. Photograph of the Unisearch LasIR ${ }^{\mathrm{TM}}$ electronics and display................................................... 4

3. Fiber-coupled tunable diode laser used in $\operatorname{LasIR}^{\mathrm{TM}}$ frequency-modulated spectrometer ................... 4

4. Laboratory setup used to evaluate impact of elevated pressure and temperature on

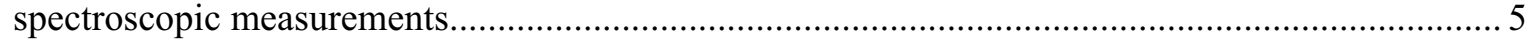

5. Photograph of experimental setup for condensate measurements ............................................... 6 
6. Plot illustrating $\mathrm{H}_{2} \mathrm{~S}$ detection sensitivity at ambient pressure and temperature

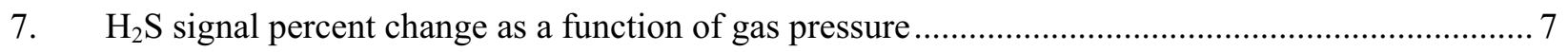

8. Absorption wavelength broadening in response to increases in pressure....................................... 7

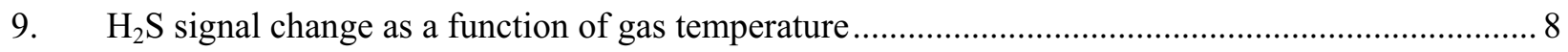

10. $\mathrm{HCl}$ detection sensitivity at ambient pressure and temperature ....................................................

11. $\mathrm{HCl}$ absorption line intensity plotted as a function of elevated pressure and temperature............... 9

12. Combined effect of pressure and temperature on $\mathrm{HCl}$ absorption signal .................................... 10

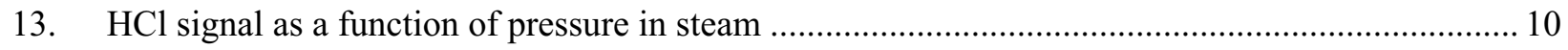

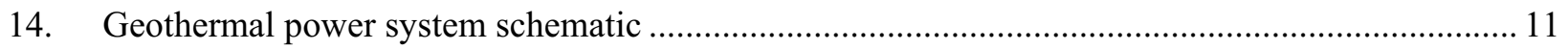

15. Side stream tap used for accessing untreated vent gas stream.................................................... 12

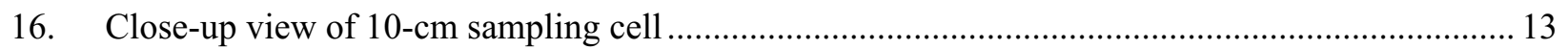

17. Near-infrared spectroscopy system installed in the untreated vent gas stream at NCPA................ 13

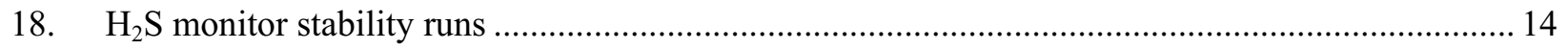

19. $\mathrm{H}_{2} \mathrm{~S}$ monitor overnight data collection from the untreated vent gas stream ................................ 15

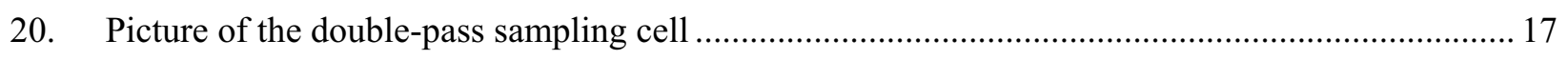

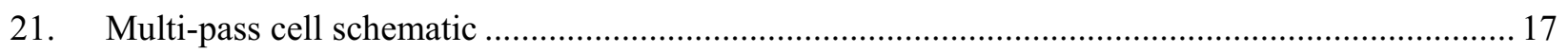

22. Comparison of $20-\mathrm{m}$ double pass tube cell and 100-m multi-pass White cell signals

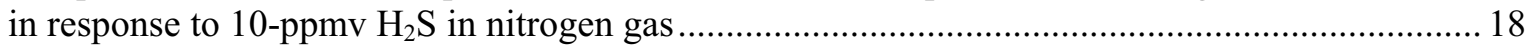

23. Overview and close-up images of treated vent gas stream sampling location ............................. 19

24. Multi-pass cell (left) and near-infrared spectroscopy instrumentation (right) deployed behind Houston Atlas system at NCPA Unit 1.

25. $3 \frac{1}{2}$ day $\mathrm{H}_{2} \mathrm{~S}$ monitor operation in NCPA Unit 1 treated vent gas stream ...................................20

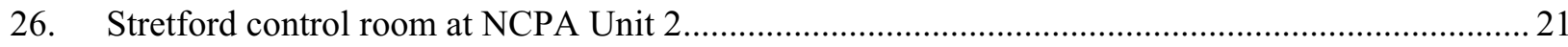

27. Fiber-coupled spectroscopy instrumentation (left) located in control room. Multi-pass cell and auto-calibration hardware (right) housed in boxes outside

28. $\mathrm{H}_{2} \mathrm{~S}$ concentration collected on-line in the treated vent gas stream using the multi-pass cell and automatic calibration unit..... 


\section{TABLES}

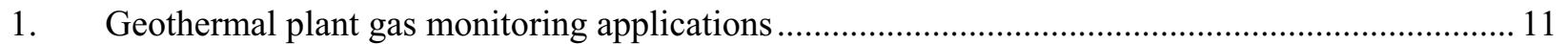

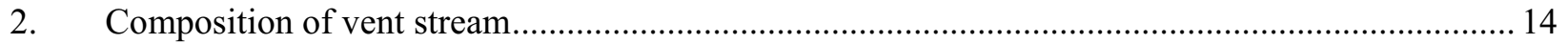




\section{Investigation of Tunable Diode Spectroscopy for Monitoring Gases in Geothermal Plants}

\section{INTRODUCTION}

This objective of this work was to identify, develop, and evaluate real-time, low maintenance systems for monitoring process gas species in geothermal power plants. In particular, the application of instrumentation based upon near-infrared, tunable diode, laser spectroscopy has been investigated for the on-line monitoring of hydrogen sulfide $\left(\mathrm{H}_{2} \mathrm{~S}\right)$ and hydrogen chloride $(\mathrm{HCl})$ gases.

The development of new $\mathrm{H}_{2} \mathrm{~S}$ monitoring systems is of interest to reduce the cost of abatement processes used to limit its emission into the atmosphere. The primary abatement uses conventional oxidation methods, including Stretford, LO-CAT ${ }^{\circledR}$, sulferox, and incineration, to reduce $\mathrm{H}_{2} \mathrm{~S}$ in the noncondensable steam vented from the condenser. The secondary abatement uses an iron chelate concentration in the cooling water to oxidize the $\mathrm{H}_{2} \mathrm{~S}$ partitioned in the steam condensate used for cooling water make-up. ${ }^{1-3}$ These abatement processes increase the operating and maintenance costs for geothermal plants. The instrumentation currently used to control these processes is labor-intensive to operate. (It is estimated that at least a man-week per month is required to maintain these instruments and to keep them in calibration.) And while these measurements are very sensitive to $\mathrm{H}_{2} \mathrm{~S}$, the long-term accuracy and precision of the instruments is not well understood. At present the $\mathrm{H}_{2} \mathrm{~S}$ levels in the cooling tower stack are measured periodically via a time-consuming sampling procedure. This infrequent sampling results in a conservative use of chemical feedstocks to ensure that regulatory limits are never exceeded. Presently, operators target chemical usage to achieve no more than $75 \%$ of allowable emissions. If this level could be raised to around $90 \%$ through the use of new continuous monitoring techniques, then annual savings on the order of $\$ 75,000$ per plant might be possible from the reduced chemical usage. $\mathrm{HCl}$ is also found in the steam delivered to geothermal production facilities. ${ }^{4}$ The washing process that reduces its concentration to acceptable levels in order to prevent corrosion of plant components also reduces the steam's energy content. ${ }^{5}$ The ability to perform cost-effective, real-time monitoring of $\mathrm{HCl}$ could also allow the optimization of this process, increasing power generation.

Near-infrared, tunable diode spectroscopy offers several benefits over other systems for geothermal emission and process control applications. ${ }^{6-9}$ In particular, the spectroscopy takes advantage of diode laser devices that have been developed for the telecommunications industry. These types of lasers produce relatively large power densities $(\sim 10 \mathrm{~mW})$ with good spectral purity $(1-3 \mathrm{GHz}$ linewidth) for high sensitivity, high selectivity measurements. They can be manufactured to emit radiation in the 0.7 to 2.0 micron region of the electromagnetic spectrum. This region contains the overtone and combination absorption bands of a number of species of industrial interest, including $\mathrm{H}_{2} \mathrm{~S}, \mathrm{HCl}, \mathrm{CO}_{2}, \mathrm{H}_{2} \mathrm{O}, \mathrm{NH}_{4}, \mathrm{O}_{2}$, $\mathrm{NO}_{2}$ and $\mathrm{CH}_{4}$. A particular diode device can be tuned over a small range by changing its applied temperature and current, providing access to the absorption band of the gas species of interest while minimizing measurement interferences by other species. The devices are compact, operate at room temperature, and have modest power requirements. In addition, the output from these systems can be easily propagated over standard communication-grade optical fibers. This allows for the configuration of a system in which the sensitive optical and electronic components can be located in an environmentallycontrolled area, and also allows the multiplexing of signals so that a single device could be used to make a number of measurements throughout the plant.

The feasibility of using this technology in geothermal process streams has been explored. ${ }^{10}$ The results of laboratory and field studies are presented along with new advances in laser technology that could allow more sensitive and selective measurements to be performed. 


\section{TECHNICAL APPROACH}

\subsection{Tunable Diode Laser Absorption Spectroscopy}

The measurements were based upon the well-known Beer-Lambert relationship that determines how much light will be transmitted through a uniform absorbing medium. This relationship is described as,

$$
\tau(v)=\frac{I(v)}{I_{0}}=\exp [-\kappa(v) L]
$$

where $\tau(v)$ is the transmission at frequency $v, \mathrm{I}_{0}$ is the incident probe beam intensity, $\mathrm{I}(v)$ is the intensity recorded at frequency $v$ after traveling through a length $L$ of the absorbing medium, and $\kappa(v)$ is the spectral absorption coefficient in units of inverse centimeters $\left(\mathrm{cm}^{-1}\right)$. The wavelength, $\lambda$, of the probe beam is related to the frequency, $v\left(\mathrm{~cm}^{-1}\right)$, by

$$
v\left(\mathrm{~cm}^{-1}\right) \equiv \frac{1}{\lambda(\mathrm{cm})}
$$

The absorption coefficient is described by the following equation,

$$
\kappa(v)=\mathrm{NS}\left(v_{0}\right) \varphi\left(v-v_{0}\right)
$$

where $\mathrm{N}$ is the concentration of the absorbing species in units of molecules $/ \mathrm{cm}^{-1}, \mathrm{~S}(\mathrm{v})$ is the line strength of the absorption transition centered at $v_{0}$ in units of cm-molecule ${ }^{-1}$, and $\varphi\left(v-v_{0}\right)$ is the line-shape function expressed in $\mathrm{cm}$.

Reviewing these basic equations, it is noted that there are several ways to for an instrument designer to increase the measurement sensitivity: (1) choose a probe wavelength that has a large absorption coefficient; (2) use a long optical path; and/or (3) measure smaller absorbed power levels.

\subsection{Frequency Modulation Techniques}

One technique for reducing the measurement noise; and thereby, detecting smaller absorbed signals is to use special modulation schemes. Frequency modulation techniques are particularly easy to implement with diode lasers since they can be tuned over small frequency ranges simply by changing the electric current passing through them. ${ }^{11-12}$

The technique is illustrated in Figure 1. The injection current of a diode is sinusoidallymodulated in frequency as the laser wavelength is tuned across the absorption line. In frequency space, the modulated laser beam consists of a carrier frequency, which is the emission frequency of the laser, and side bands displaced from the carrier by integral multiples of the modulation frequency. When this light impinges on a photodetector, each side band mixes with the carrier to give a signal at the modulation frequency. Since the side bands are equal and opposite in phase the two signals generated by the mixing process cancel unless their relative amplitudes and phases are altered in the measurement process. For trace gas detection, this alteration is arranged by adjusting the laser emission and modulation frequencies so that a strong line of the molecular species of interest overlaps one of the side bands. 

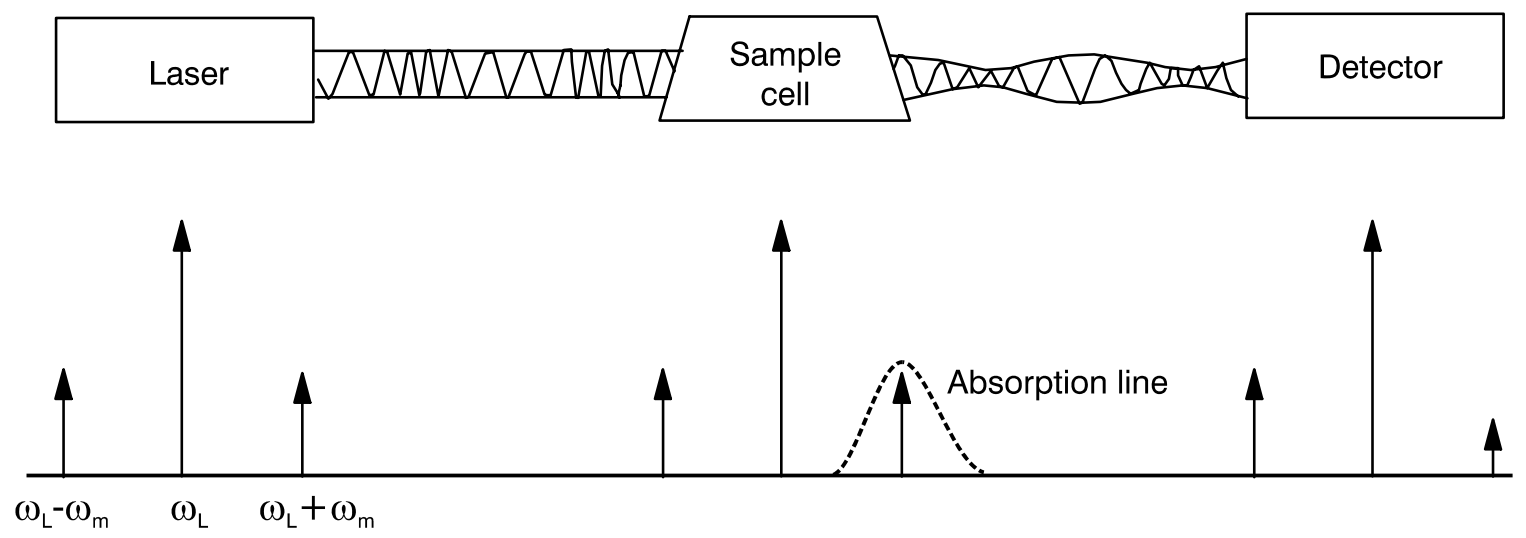

Frequency-modulated optical beam becomes amplitude-modulated

Figure 1. Frequency modulated spectroscopy concept.

J970245

The advantage of this technique is that the measurement can be performed at frequencies where other noise sources are minimized; and therefore, very sensitive measurements are possible. In addition, the properties of the laser diode can be controlled so that it only tunes over the absorption line of the species of interest, minimizing signal contributions from potential interfering species in the process streams such as water vapor or carbon dioxide. The detection of gas absorbances as low as $10^{-7}$ are possible under laboratory conditions.

One practical difficulty in achieving this sensitivity in industrial applications is due to the requirement that the modulation frequency, and corresponding detector bandwidth, be on the order of the linewidth of the species to be detected and measured. For atmospherically broadened $(10 \mathrm{GHz})$ lines, this is readily accomplished using a two-tone modulation technique in which a pair of closely-spaced frequencies are used to modulate the laser. ${ }^{13-14}$ The detector output is then demodulated at the difference frequency. This technique permits high-modulation frequencies matched to pressure-broadened lines using modest bandwidth detectors. For example, a two-tone technique could be employed that modulated the laser at 10,000,000,000 Hz and 10,001,000,000 Hz; and consequently, performed the demodulation and detection at $1 \mathrm{MHz}$.

While frequency-modulated detection schemes have proven very sensitive under low pressure and atmospheric conditions, the additional line broadening that occurs under conditions of high pressure and elevated temperature can significantly limit the effectiveness of the technique. ${ }^{15}$ (The line shape function $\varphi\left(v-v_{0}\right)$ from Equation 3 changes with temperature due to Doppler broadening and with both pressure and temperature through collision, or pressure, broadening.) Environmental conditions at geothermal plants vary from the main stream line which operates at a temperature of about $350^{\circ} \mathrm{F}\left(175^{\circ} \mathrm{C}\right)$ and a pressure of 100 psig to the cooling stack with a temperature of $80-100^{\circ} \mathrm{F}\left(27-38^{\circ} \mathrm{C}\right)$ at ambient pressure. Scattering from condensate and other particulate may also reduce the signal transmission to unusable levels. Consequently, a key goal of this investigation was to evaluate the response of a nearinfrared tunable spectrometer under these types of conditions. This data could then be used to determine which plant locations and instrument configurations were optimal for the deployment of on-line monitoring systems. 


\section{LABORATORY EXPERIMENTS}

\subsection{Instrumentation}

The frequency-modulated, diode laser spectroscopy components were procured from Unisearch Associates (Ontario, Canada). The components included a distributed feedback, tunable laser diode, a small telescope and retroreflector assembly, 20-m and 100-m multi-pass sampling cells, and a controller module. The controller module, pictured in Figure 2, contains the diode laser and the circuitry for tuning and stabilizing the laser; a reference cell for locking the laser wavelength onto the absorption feature; the radio frequency modulation circuitry; signal and reference detectors and their associated circuitry; a data acquisition board; and an on-board computer for automated control and communication with an external personal computer for data logging and display purposes. This system is packaged into a $46 \times 22 \times 45-\mathrm{cm}$ size box. A close-up view of the diode laser is presented Figure 3.

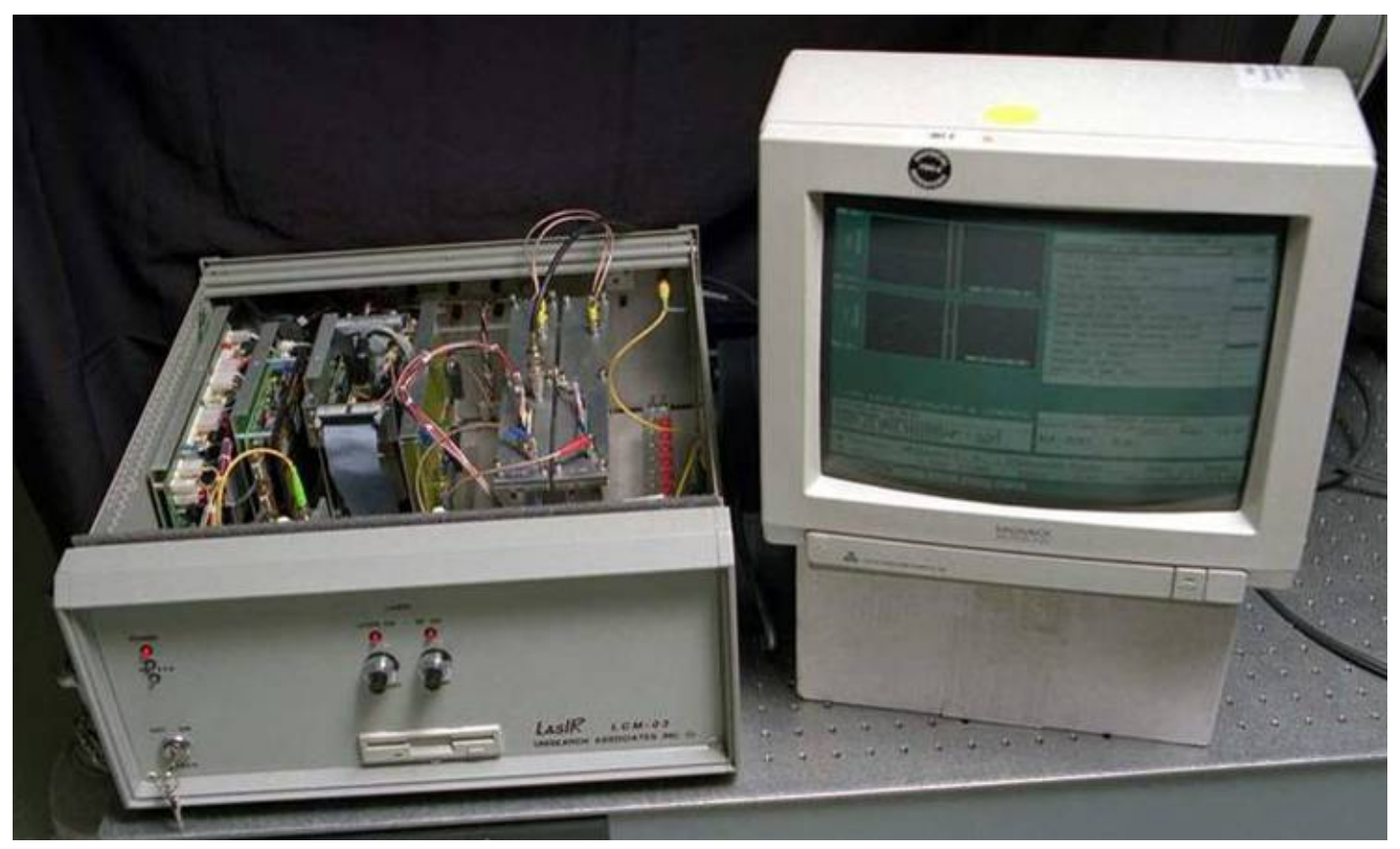

Figure 2. Photograph of the Unisearch LasIR ${ }^{\mathrm{TM}}$ electronics and display.

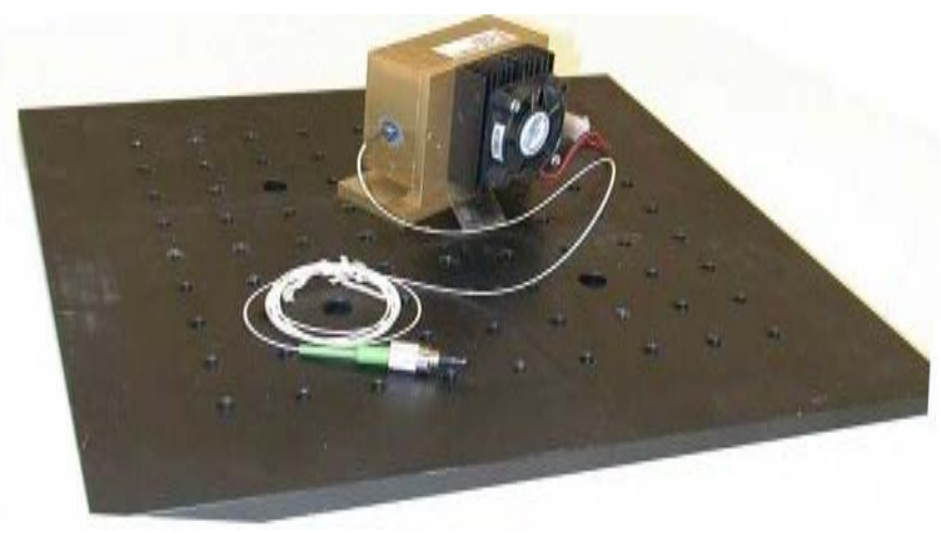

Figure 3. Fiber-coupled tunable diode laser used in LasIR ${ }^{\mathrm{TM}}$ frequency-modulated spectrometer. 
For the initial laboratory experiments aimed at evaluating the impact of pressure and temperature on the measurement sensitivity, a stainless steel test cell, $80 \mathrm{~cm}$ in length and $2.54 \mathrm{~cm}$ in diameter, was configured with sapphire windows. The cell was designed to be placed in a clam shell furnace for operation at high temperature; and in addition, could be pressurized to at least 7 atmospheres (100 psig). The cell also incorporated flow controllers to allow the introduction of calibrated gas and water vapor. The laser radiation was transmitted to the cell over a single mode optical fiber and collimated into a narrow beam by a grin lens coupled to the end of the fiber. The beam was then propagated through the cell and detected at the opposite end using a germanium detector. The Unisearch LasIR system was used to control and modulate the beam, as well as to demodulate and analyze the signals. A schematic of this setup is presented in Figure 4.

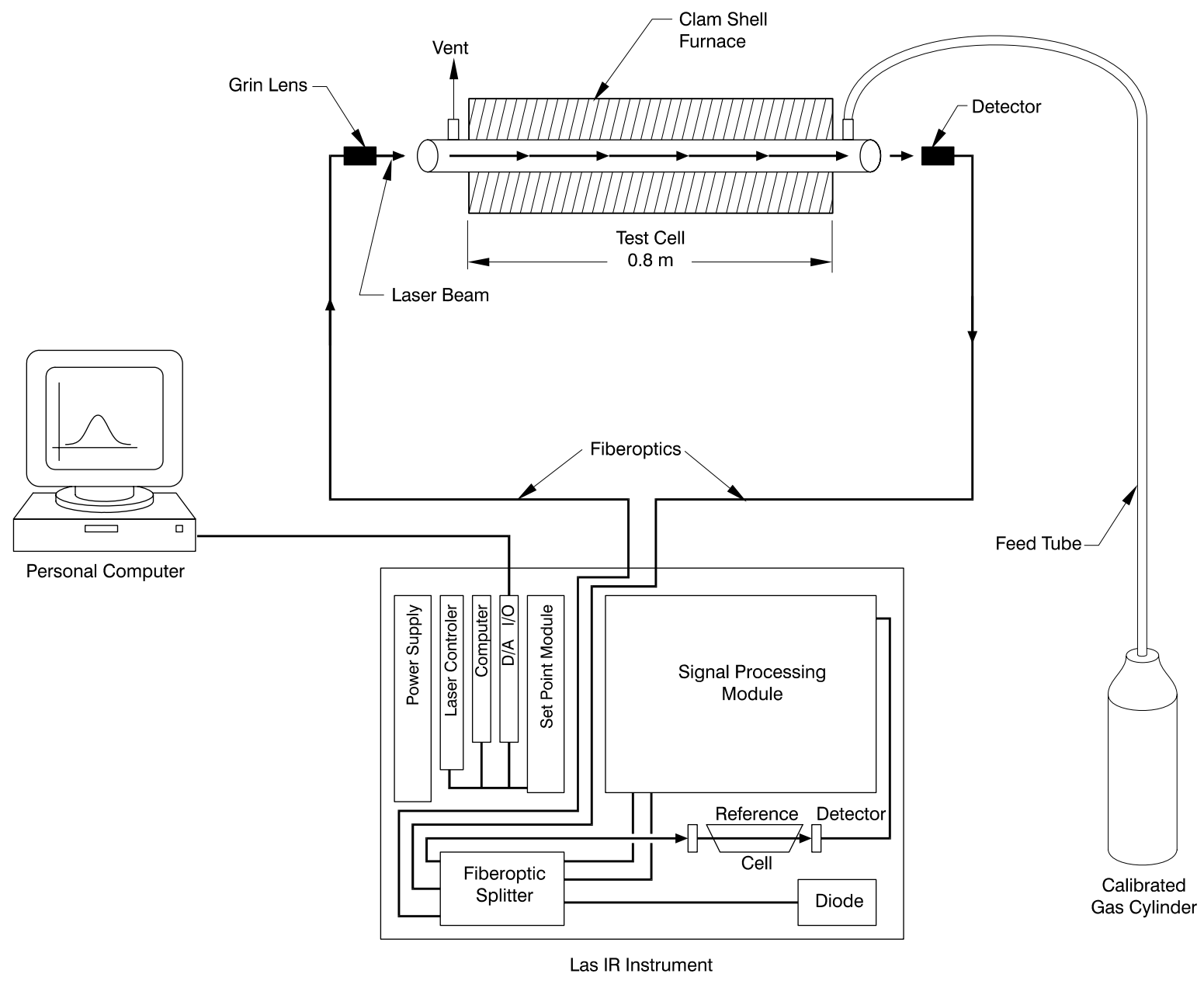

F98 0056

Figure 4. Laboratory setup used to evaluate impact of elevated temperature and pressure on spectroscopic measurements.

A separate fixture, a plexiglass box $(100 \times 35 \times 35-\mathrm{cm}$ in dimension $)$ was configured with access holes to accommodate the telescope and retroreflector assembly for use in the tests to evaluate the response of the device in the presence of condensate. For this work, the 10-m calibration cell was filled with 5000-ppmv $\mathrm{H}_{2} \mathrm{~S}$ in nitrogen gas. (The term ppmv refers to the concentration of the species in ppm by volume.) Heated vapor from a boiling flask of water was then introduced into the containment box and the effect on the existing signal was observed. A picture of this set-up is shown in Figure 5. 


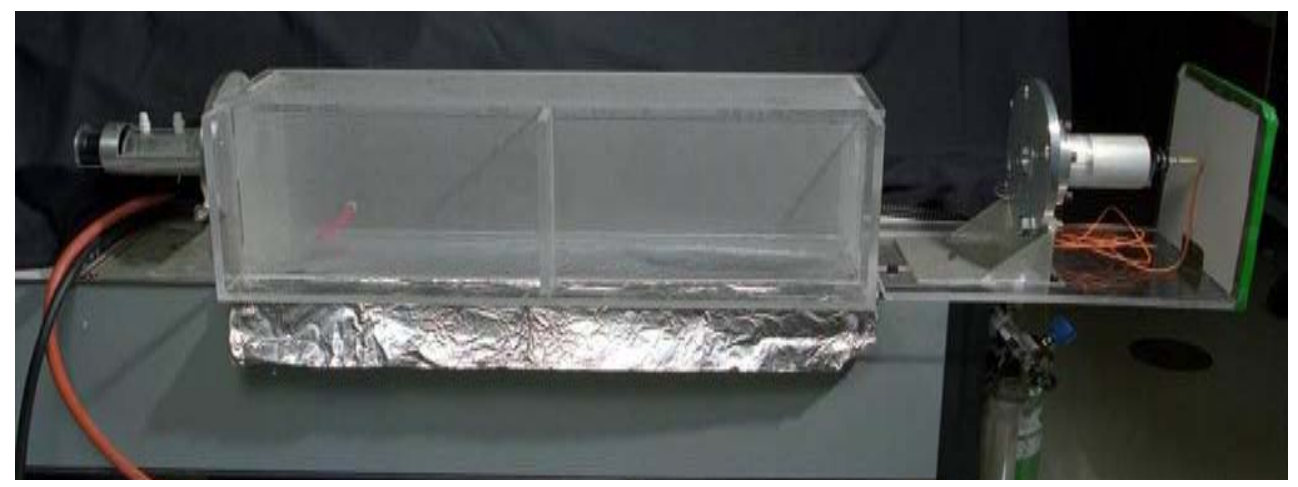

Figure 5. Photograph of experimental setup for condensate measurements.

\subsection{Hydrogen Sulfide $\left(\mathrm{H}_{2} \mathrm{~S}\right)$ Measurements}

The sensitivity and detectivity of the device was evaluated by filling the calibration cell with various mixtures (500 and 1000 ppmv in nitrogen) of $\mathrm{H}_{2} \mathrm{~S}$ from calibration cylinders and observing the standard deviation in the signal. An example of a plot of this type of data is present in Figure 6.

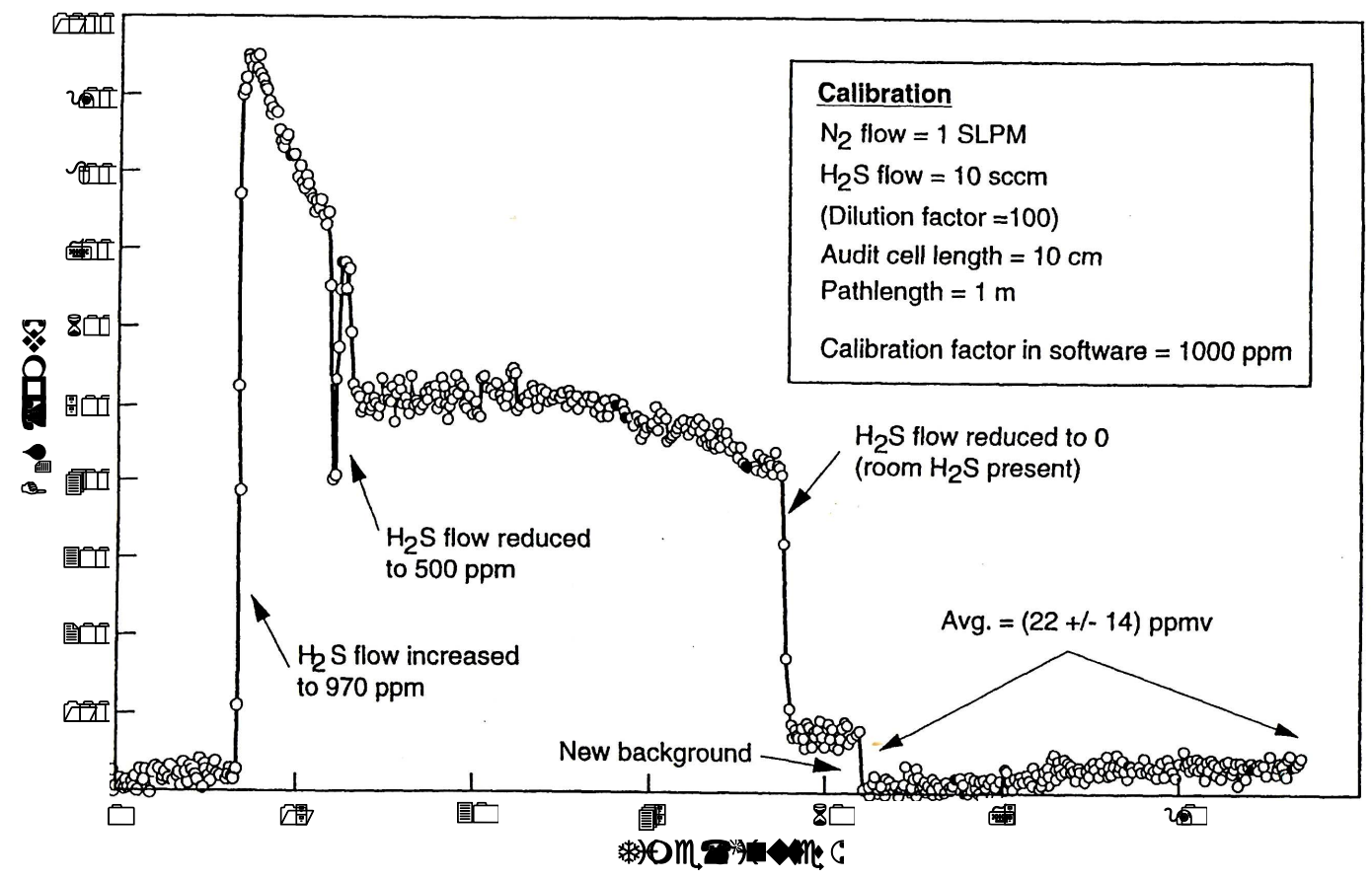

Figure 6. Plot illustrating $\mathrm{H}_{2} \mathrm{~S}$ detection sensitivity at ambient pressure and temperature.

A detection limit on the order of around $25 \mathrm{ppmv}$ per meter was readily obtainable with the device. Some signal noise modulation due to optical feedback into the laser diode was observed in the signals. It is speculated that by improving the optical isolation in the system this noise could be reduced and the detection limit improved. 
The response of the system to changes in pressure is shown in Figures 7 and 8 . For these experiments, the stainless steel cell was filled with 5000-ppmv $\mathrm{H}_{2} \mathrm{~S}$ gas to various pressures. The data indicate that the measurement is quite sensitive to changes in pressure, exhibiting a $50 \%$ decrease in signal for every 5 psig ( $\sim 1 / 3$ atmosphere) increase in pressure. The poor response of the instrument at high pressure is not unexpected since the analytical technique, to a first approximation, measures the derivative of the absorption line. As noted in Figure 8, the absorption line broadens in response to increases in pressure; and therefore, the slope (derivative) of the line decreases, along with the measurement sensitivity.

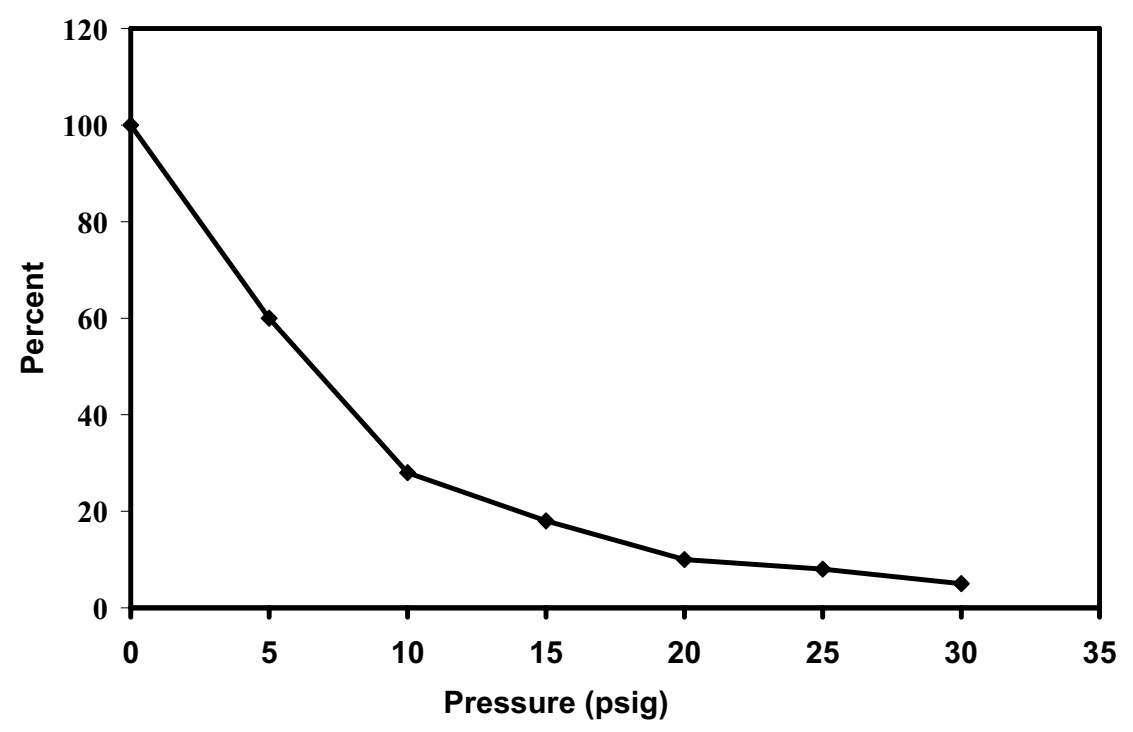

Figure 7. $\mathrm{H}_{2} \mathrm{~S}$ signal percent change as a function of gas pressure.

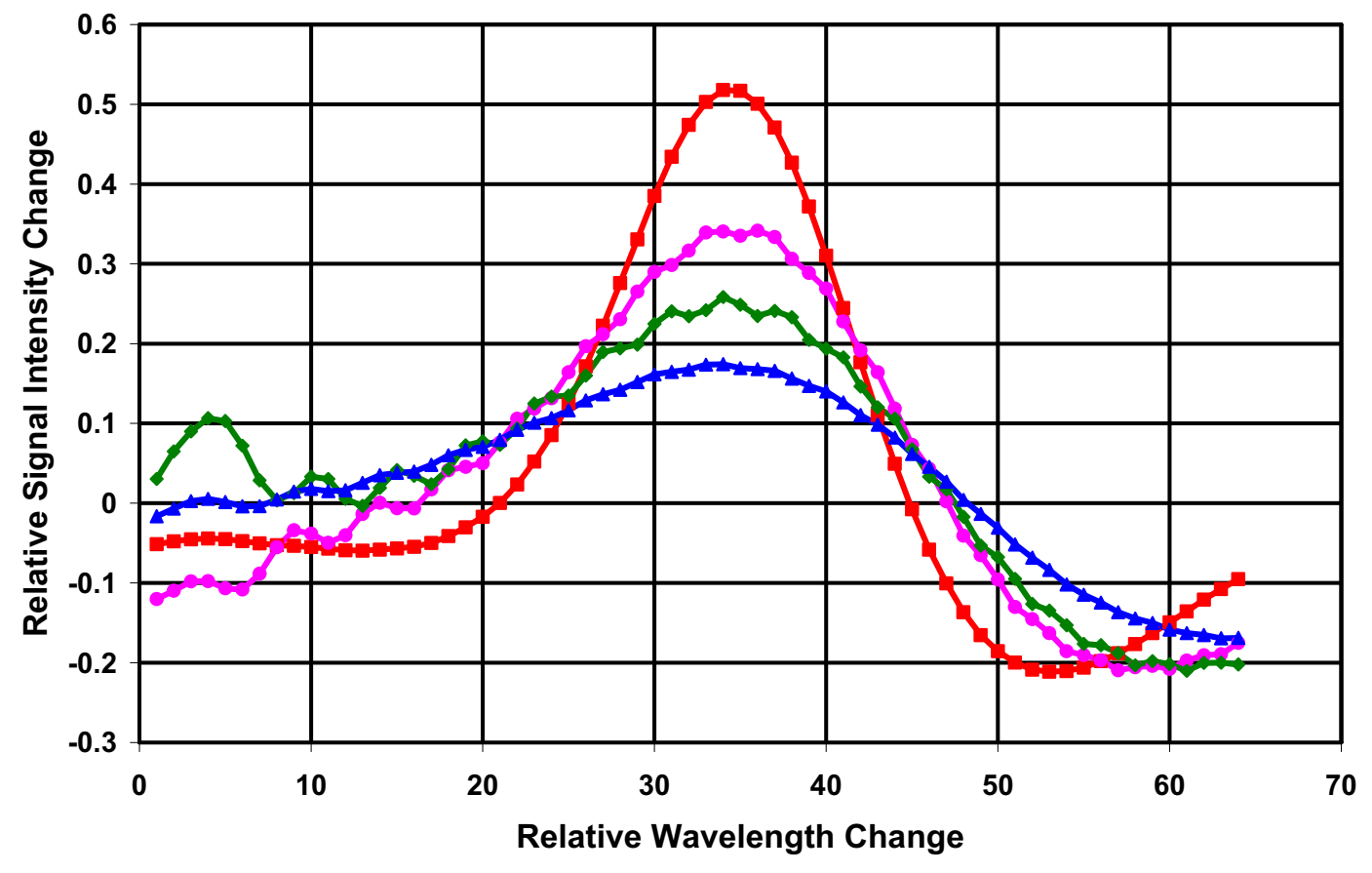

$\rightarrow 0.2 \mathrm{~atm} \rightarrow 0.4 \mathrm{~atm} \rightarrow 0.6 \mathrm{~atm} \rightarrow 0.8 \mathrm{~atm}$

Figure 8. Absorption wavelength broadening in response to increases in pressure. 
The sloping background observed in this data is due to an etalon effect. This effect occurs because the windows in the stainless steel cell were not angled relative to the propagating beam, resulting in the generation of a broad interference fringe that is detected by the device as a change in intensity. It is possible to reduce the impact of this effect using a quadratic suppression technique. In this technique, a quadratic function of the form, $\mathrm{y}=1+\mathrm{bx}+\mathrm{cx}^{2}$ is fitted to the signal and reference spectra. The spectra are then divided by the fitted functions, effectively removing the baseline and making the function more symmetric prior to the analysis step.

The device exhibited much less sensitivity to changes in temperature. Signal changes of less than $20 \%$ were observed over the temperature range of $20^{\circ} \mathrm{C}\left(68^{\circ} \mathrm{F}\right)$ to $155^{\circ} \mathrm{C}\left(310^{\circ} \mathrm{F}\right)$. The signal change as a function of temperature is plotted in Figure 9. Laboratory testing was also performed with water vapor at ambient temperature and pressure. These experiments indicated that the device was effective at excluding the contribution of water vapor in the signal. However, a marked decrease in signal-to-noise was observed as droplets formed which were comparable to the size of the wavelength of light, i.e. the device did not function well in the presence of fog. In the tests, the device was able to operate with reasonable signal-tonoise after a loss of up to $80 \%$ of the initial signal.

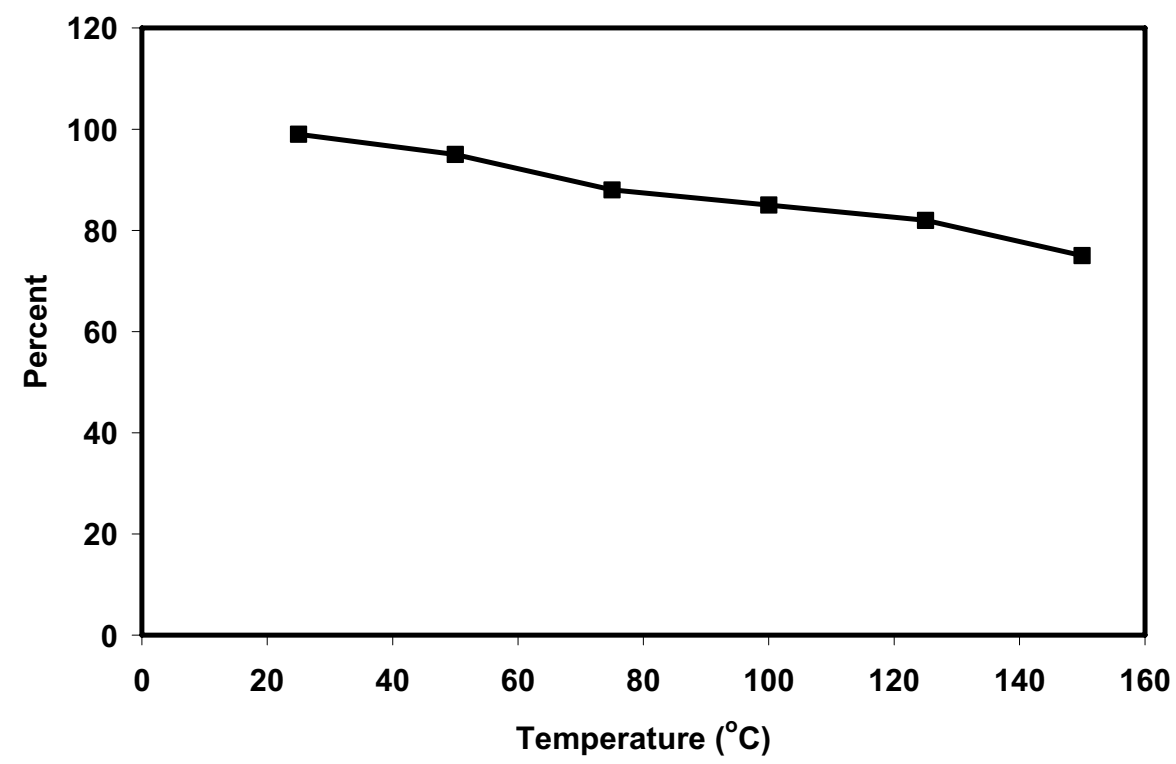

Figure 9. $\mathrm{H}_{2} \mathrm{~S}$ signal change as a function of gas temperature.

\subsection{Hydrogen Chloride $(\mathrm{HCl})$ Measurements}

For the $\mathrm{HCl}$ measurements, the 1.578-micron laser diode used to detect $\mathrm{H}_{2} \mathrm{~S}$ was replaced with a 1.793-micron device corresponding to a $\mathrm{HCl}$ absorption band. The ability of the tunable laser spectroscopy instrument to detect $\mathrm{HCl}$ was evaluated by filling the test cell with various mixtures $(\sim 50$ and 500 ppmv in nitrogen) of $\mathrm{HCl}$ gas from calibration cylinders. An example of a typical data run is presented in Figure 10. A detection limit of approximately 1.0 ppmv per meter was observed in the measurements collected at atmospheric pressure. The detection sensitivity, which is theoretically on the order of $0.1 \mathrm{ppmv}$ per meter, was primarily limited by etalon and laser feedback noise at the low concentrations. 


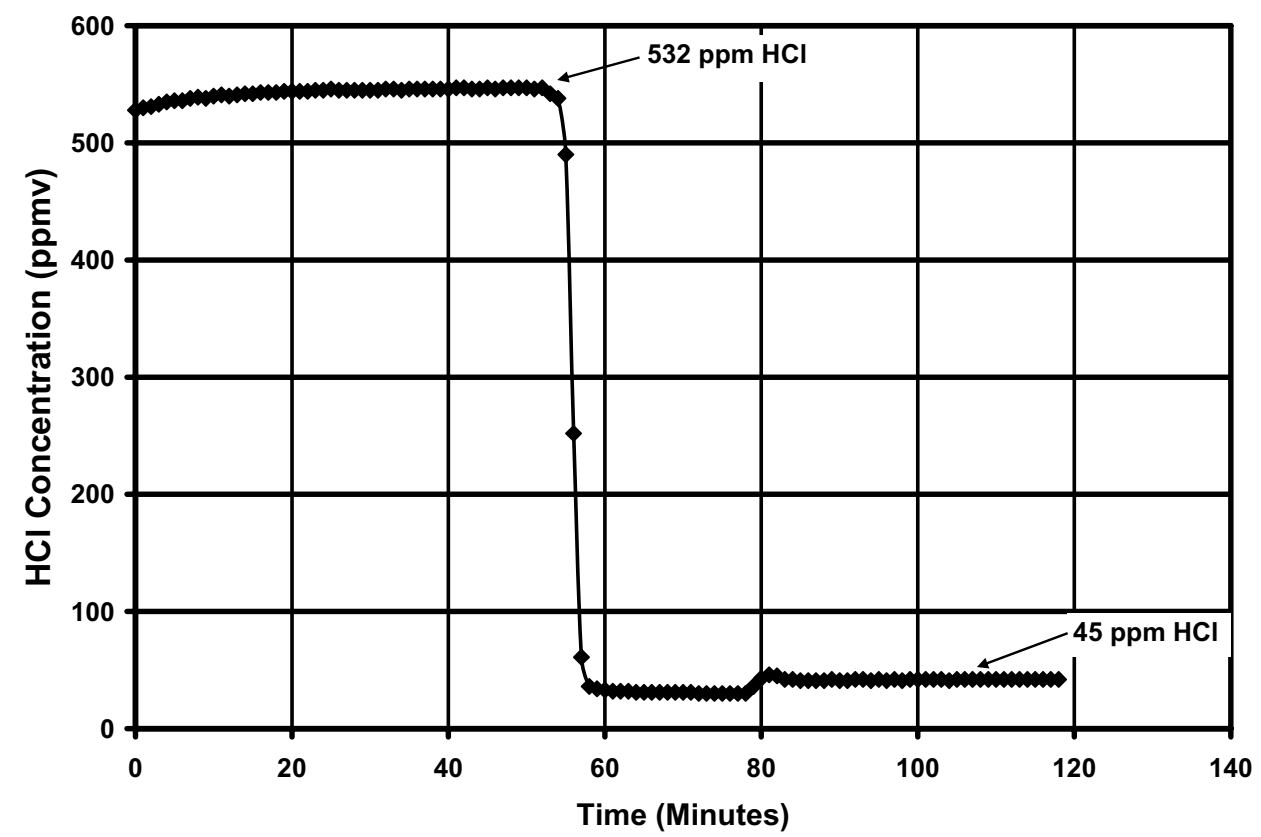

Figure 10. $\mathrm{HCl}$ detection sensitivity at ambient pressure and temperature.

The response of the system to changes in pressure and temperature are illustrated in Figure 11. This data was collected by filling the stainless steel cell with 500-ppmv $\mathrm{HCl}$ regulated at pressures up to approximately $20 \mathrm{psig}$. Similarly, the temperature data was collected by filling the cell with 500 -ppmv $\mathrm{HCl}$ gas and heating the cell to a temperature of around $150^{\circ} \mathrm{C}$. These plots indicate that the measurement is quite sensitive to pressure, exhibiting a $55 \%$ decrease in signal intensity due to broadening of the absorption line over the range tested. (This effect is considerably less sensitive; however, than that measured with $\mathrm{H}_{2} \mathrm{~S}$ which indicated a $40 \%$ decrease in signal intensity for every 5 pounds of pressure above atmosphere.) The signal appears to be much less sensitive to changes in temperature with only a $25 \%$ percent drop recorded over the $150^{\circ} \mathrm{C}$ range. The combined response of the system to elevated pressure and temperature is presented in Figure 12. Again, pressure-broadening is seen to be the dominant signal degradation mechanism.
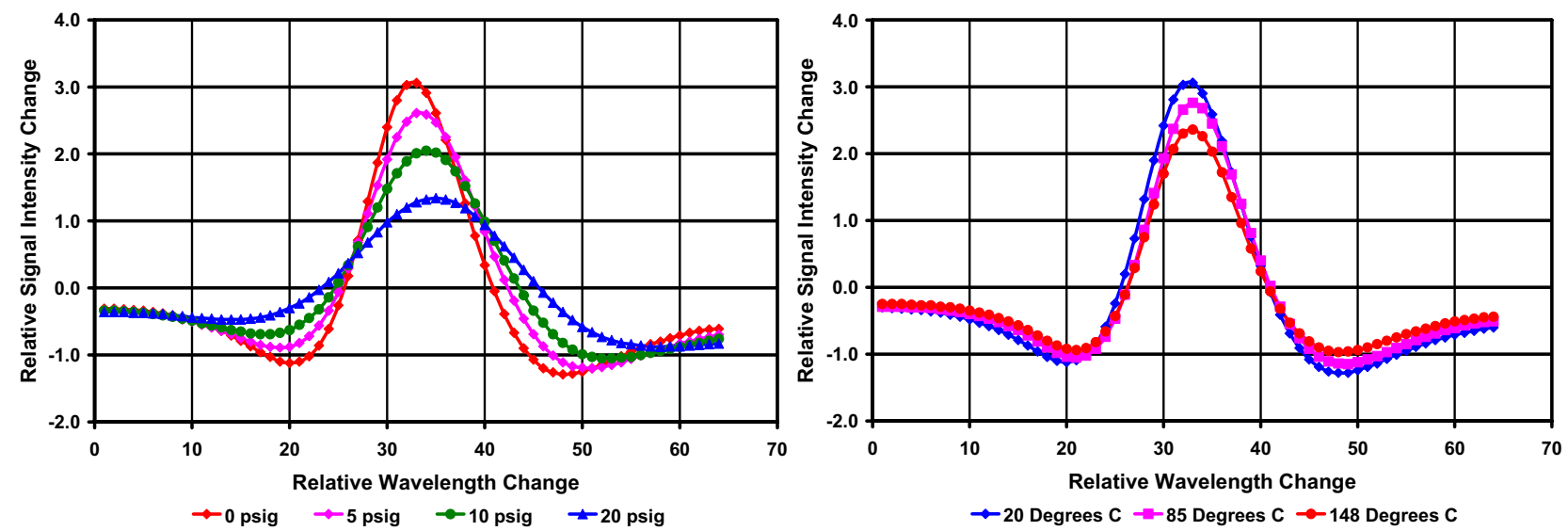

Figure 11. $\mathrm{HCl}$ absorption line intensity plotted as a function of elevated pressure and temperature. 


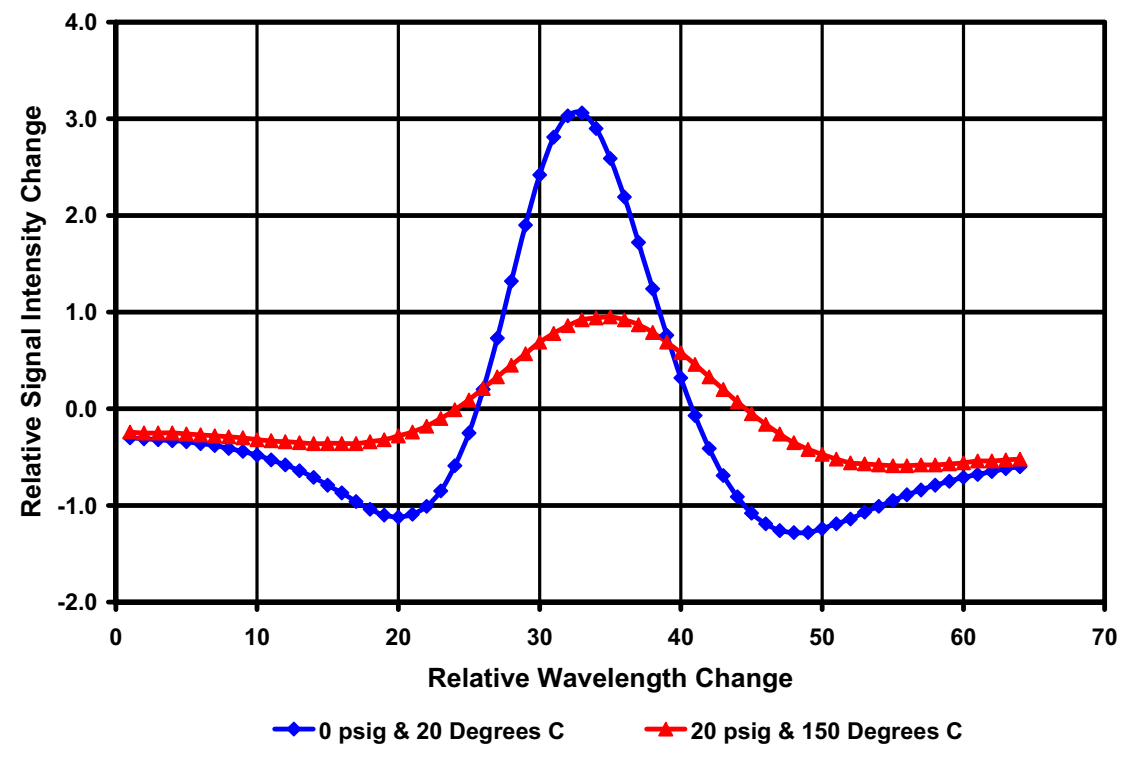

Figure 12. Combined effect of pressure and temperature on $\mathrm{HCl}$ absorption signal.

Additional testing in a high temperature, steam environment was conducted in collaboration with Thermochem, Inc. using a steam generator at their facility located in Santa Rosa, CA. These experiments indicated two problems with the instrument that need to be addressed before the system can see wide use as an on-line hydrogen chloride detection system for plant steam. First, the spectroscopic line-broadening of near-by water vapor lines produced interferences with the 1.793-micron absorption band used for detection; and second, the hydrogen chloride tended to adhere to the stainless steel sampling cell creating a residual, or background, signal. As illustrated in Figure 13, testing was performed at lower pressures to determine if the water interferences could be eliminated or minimized. Operation at pressures of around $1 / 3$ atmosphere did allow detection limits in the 50-100 ppmv range to be achieved.

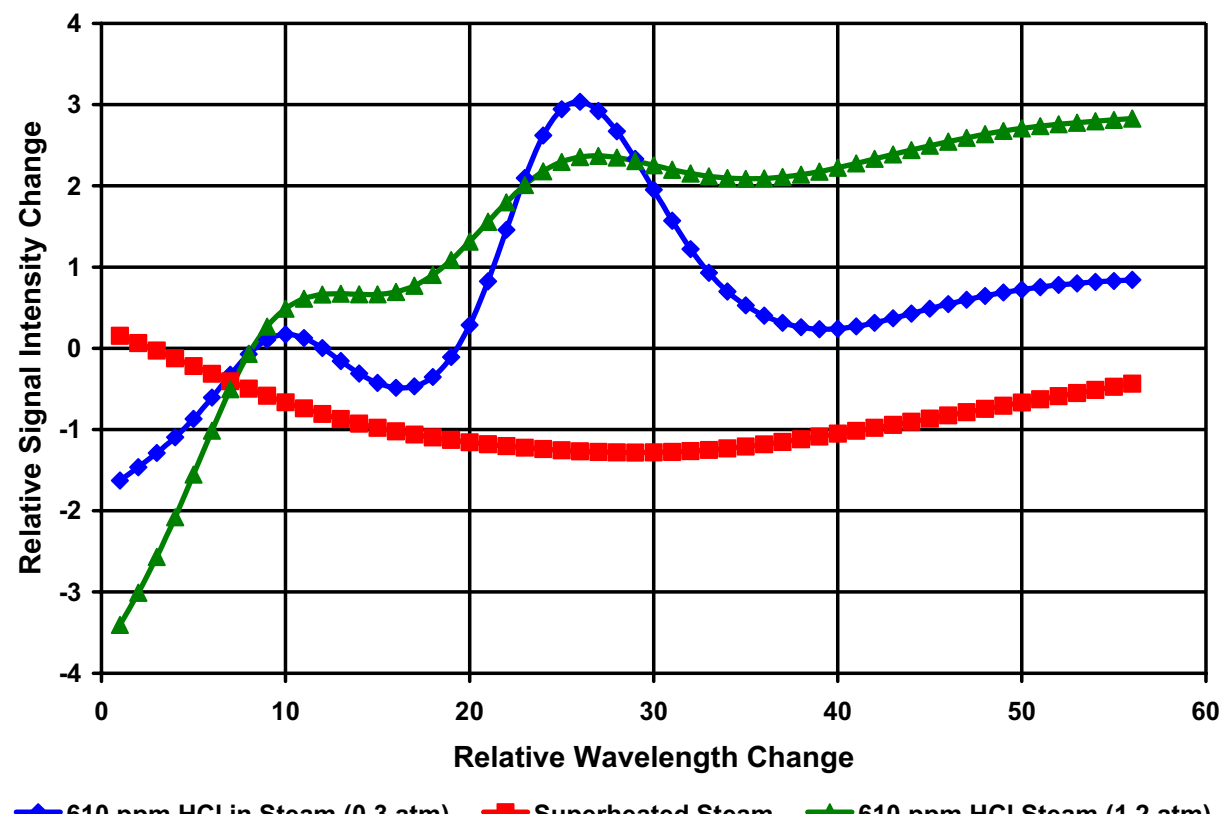

Figure 13. $\mathrm{HCl}$ signal as a function of pressure in steam. 


\section{FIELD DEPLOYMENT AND EVALUATION}

\subsection{Deployment Considerations}

From discussions with plant personnel, several locations (Figure 14) were identified and prioritized as possible positions for siting a gas monitoring system. (In addition to $\mathrm{H}_{2} \mathrm{~S}$ and $\mathrm{HCl}$, there is also some interest in extending the measurement capability to other species.) The possible applications and priorities are summarized in Table 1.

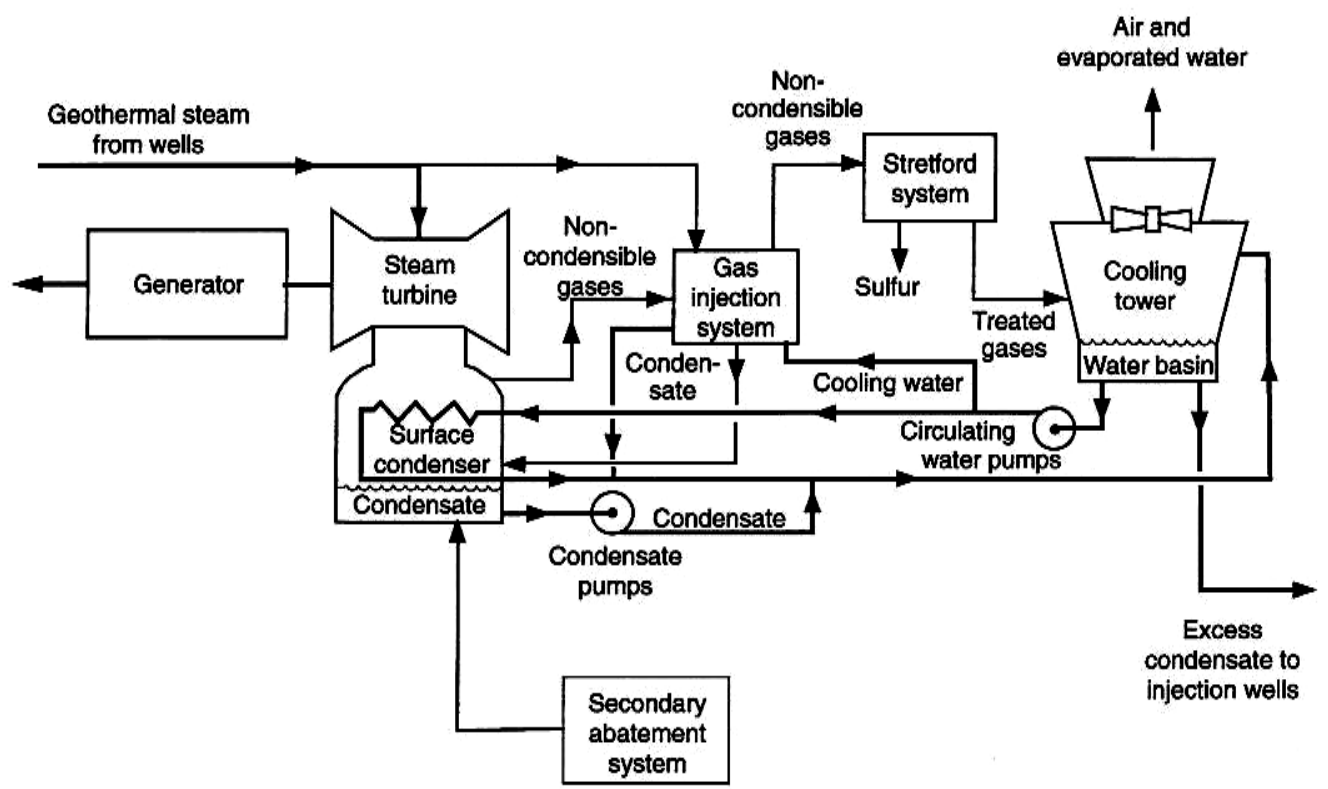

Figure 14. Geothermal power system schematic. ${ }^{3}$

J970246

Table 1. Geothermal plant gas monitoring applications.

\begin{tabular}{|c|c|c|}
\hline CHEMICAL SPECIES & $\begin{array}{c}\text { MEASUREMENT } \\
\text { LOCATION }\end{array}$ & PRIORITY \\
\hline $\mathrm{H}_{2} \mathrm{~S}$ & Cooling Tower Fan Stack & High \\
\hline $\mathrm{H}_{2} \mathrm{~S}$ & Main Steam Line & High \\
\hline $\mathrm{H}_{2} \mathrm{~S}$ & Untreated Vent Gas & Medium \\
\hline $\mathrm{O}_{2}$ & Untreated Vent Gas & Medium \\
\hline $\mathrm{HCl}_{\mathrm{SO}}$ & Main Steam Line & Low \\
\hline $\mathrm{S}_{2}$ & Treated Vent Gas & Low \\
\hline $\mathrm{CH}_{4}$ & Treated Vent Gas & Low \\
\hline $\mathrm{H}_{2} \mathrm{~S}$ & Main Steam Line & Low \\
\hline $\mathrm{H}_{2}$ & Treated Vent Gas & Low \\
\hline
\end{tabular}

Due to the sensitivity of the tunable near-infrared measurement technique to elevated pressure and temperature indicated in the laboratory studies, direct sampling of the steam line was not feasible. The lower pressure detection limit of 50-100 ppmv obtained for $\mathrm{HCl}$ in steam was also one to two orders of magnitude above the typical level of interest for steam line monitoring. In considering the cooling stack application, a detection limit of around 25 ppmv per meter was measured for $\mathrm{H}_{2} \mathrm{~S}$ at atmospheric 
pressure. Extrapolating over the 8-m diameter of a typical cooling stack, it should be possible to detect $\mathrm{H}_{2} \mathrm{~S}$ at a level of 1-2 ppmv in a signal retroreflected across the stack. Again, a typical level of interest is on the order of $100 \mathrm{ppbv}$, requiring the measurement to be performed at a lower pressure or over a longer optical path in order to achieve this level of sensitivity. Consequently, the detection of $\mathrm{H}_{2} \mathrm{~S}$ in the untreated and treated vent gas streams was chosen for evaluating the performance of the instrument in a geothermal plant process stream. The untreated vent gas stream has a $\mathrm{H}_{2} \mathrm{~S}$ concentration on the order of $25,000 \mathrm{ppmv}$, while the treated vent gas stream concentration is maintained at $0-20 \mathrm{ppmv}$. In addition to containing higher concentrations of $\mathrm{H}_{2} \mathrm{~S}$, these process streams could also be sampled at lower pressures, further enhancing the measurement sensitivity.

\subsection{On-line Measurement of $\mathrm{H}_{2} \mathrm{~S}$ in the Untreated Vent Gas Stream}

An initial field trial of the near-infrared, frequency-modulated spectroscopy system was conducted at the Northern California Power Agency (NCPA) Unit 1 plant using a side stream of the condenser vent gas entering the Stretford system. The goal of this initial test was to evaluate the operability of the device under process conditions and determine what future design modifications are needed to optimize its performance for long-term plant operation.

The test configuration is shown below. A side stream of the vent gas (Figure 15) was tapped prior to its entering the Stretford unit and passed through a 10-cm sampling cell (Figure 16). The gas leaving the sampling cell was discharged back to the suction side of the steam ejector. Two filters (seen in Figures 15 and 17) were placed in the line supplying the sample cell to remove any liquid or particulate in the gas stream before it entered the cell. The presence of $\mathrm{H}_{2} \mathrm{~S}$ then produced an absorption peak in the signal detected by the laser diode spectroscopy system (Figure 17). This peak is then correlated to one produced by a sample stream of known concentration.

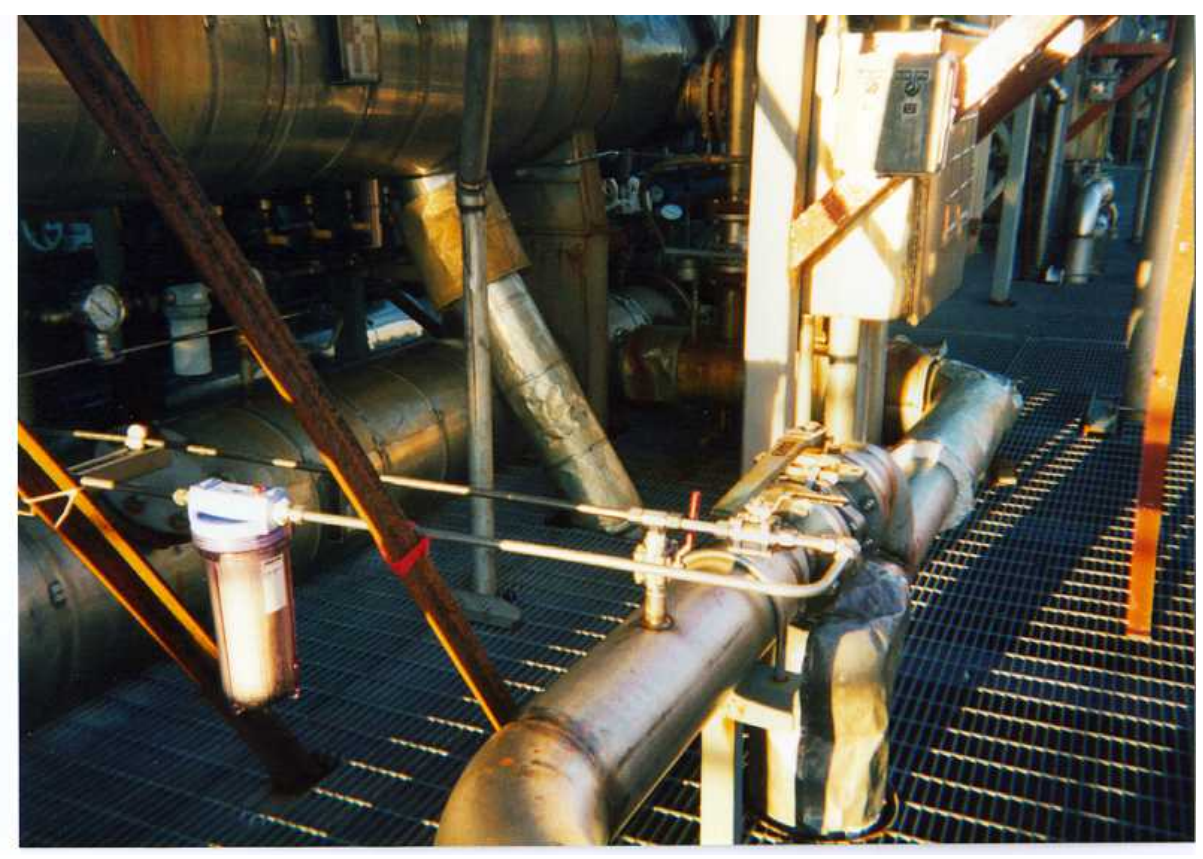

Figure 15. Side stream tap used for accessing the untreated vent gas stream. 


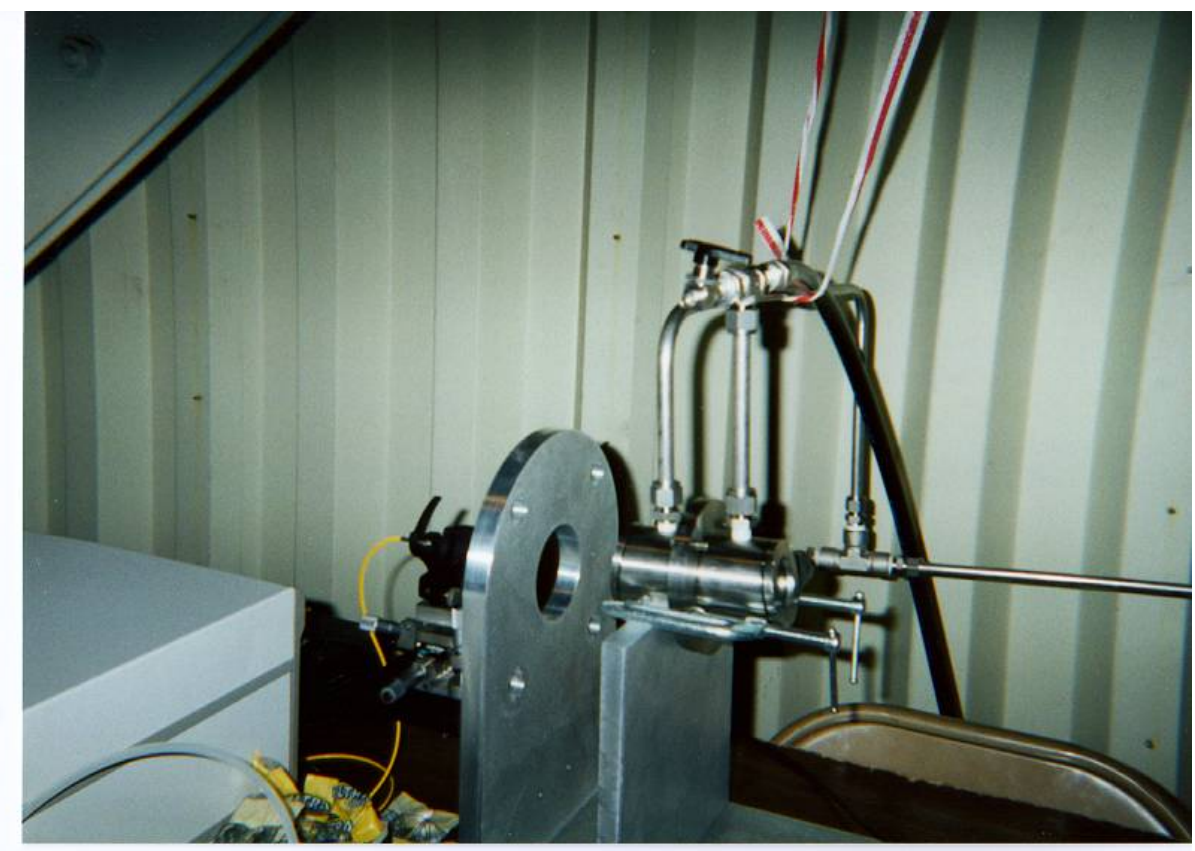

Figure 16. Close-up view of 10-cm sampling cell.

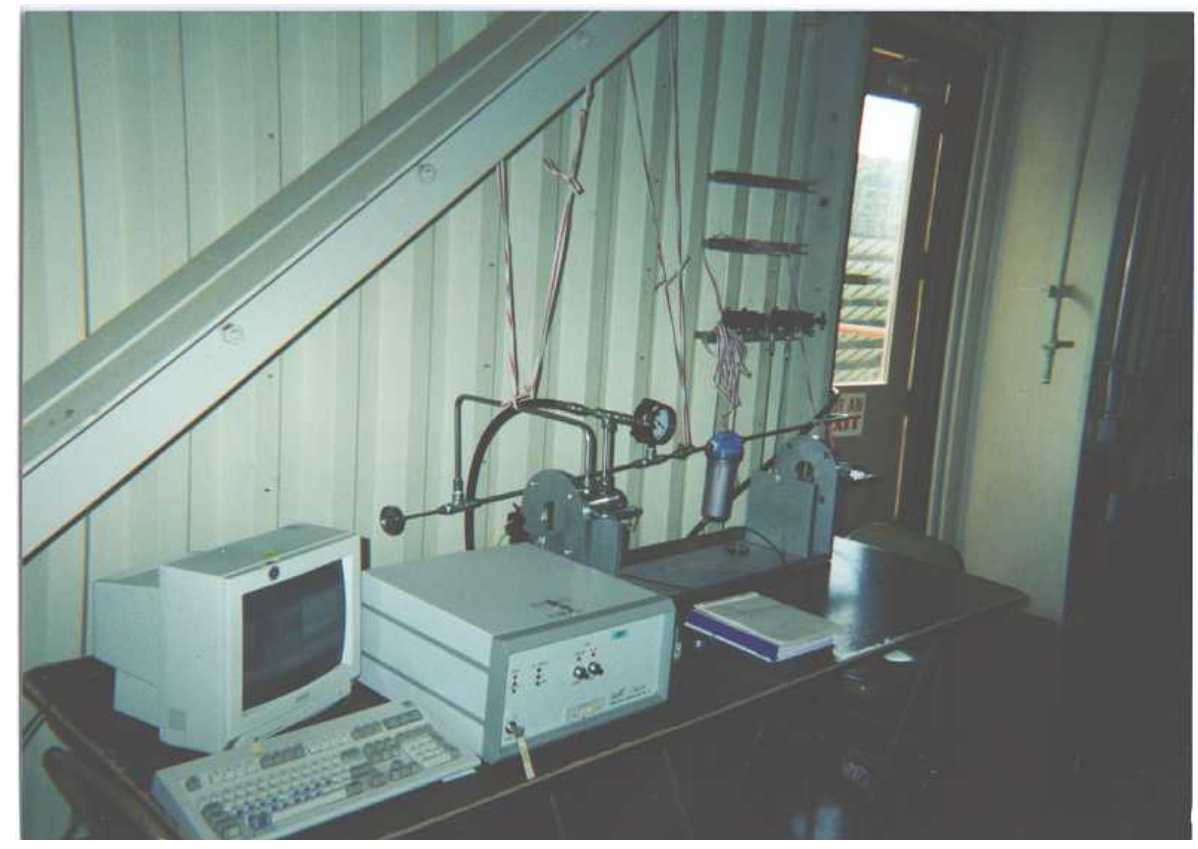

Figure 17. Near-infrared spectroscopy system installed in untreated vent gas stream at NCPA.

The controller module, previously described in Section 3.1, is placed to the right of the monitor and keyboard in Figure 17. The laser probe signal is propagated to the 10-centimeter cell via a fiber optic cable terminated with a collimating lens system. (The yellow cable pictured in Figure 16.) The collimated beam is then transmitted through the glass windows in the cell and detected by a germanium detector. This signal is propagated back to the controller module via a coaxial cable. While the sampling cell and 
controller module are placed closely together on a table for these tests, they can be operated remotely at distances up to 500 meters.

The gas stream contained $\mathrm{H}_{2} \mathrm{~S}$ in 2-3 mole percent concentrations and a mixture of other gases including $\mathrm{H}_{2}, \mathrm{CO}_{2}, \mathrm{CH}_{4}, \mathrm{O}_{2}, \mathrm{~N}_{2}, \mathrm{NH}_{4}$, and $\mathrm{H}_{2} \mathrm{O}$. The stream was controlled at a pressure of 0.7 atm with temperatures in the $20-30^{\circ} \mathrm{C}$ range. The typical stream gas composition in summarized in Table 2 .

Table 2. Composition of Vent Stream

\begin{tabular}{|c|c|}
\hline GAS SPECIES & CONCENTRATION (MOLE \%) \\
\hline $\mathrm{CO}_{2}$ & 47 \\
\hline $\mathrm{H}_{2}$ & 19 \\
\hline $\mathrm{H}_{2} \mathrm{O}$ & 18.9 \\
\hline $\mathrm{CH}_{4}$ & 7.8 \\
\hline $\mathrm{N}_{2}$ & 4.3 \\
\hline $\mathrm{H}_{2} \mathrm{~S}$ & 2.7 \\
\hline $\mathrm{NH}_{4}$ & 1.5 \\
\hline $\mathrm{O}_{2}$ & 0.8 \\
\hline
\end{tabular}

The spectroscopy system was calibrated using a certified gas mixture containing $\mathrm{H}_{2} \mathrm{~S}$ in nitrogen at $53500 \pm 535 \mathrm{ppmv}$. The measured $\mathrm{H}_{2} \mathrm{~S}$ levels were also periodically benchmarked against independent measurements using the Tutwiler method, in which a gas sample is titrated with iodine in a starch solution until a blue color signals the endpoint.

Initial test runs were performed over 5-6 hour periods to optimize the system and observe system stability and precision. Examples of these runs are presented in Figures 18. Since the calibration gas had not been delivered at this point in time, the system was given a calibration value $(27,000 \mathrm{ppmv})$ based upon the normal operating parameters supplied by the plant operator.
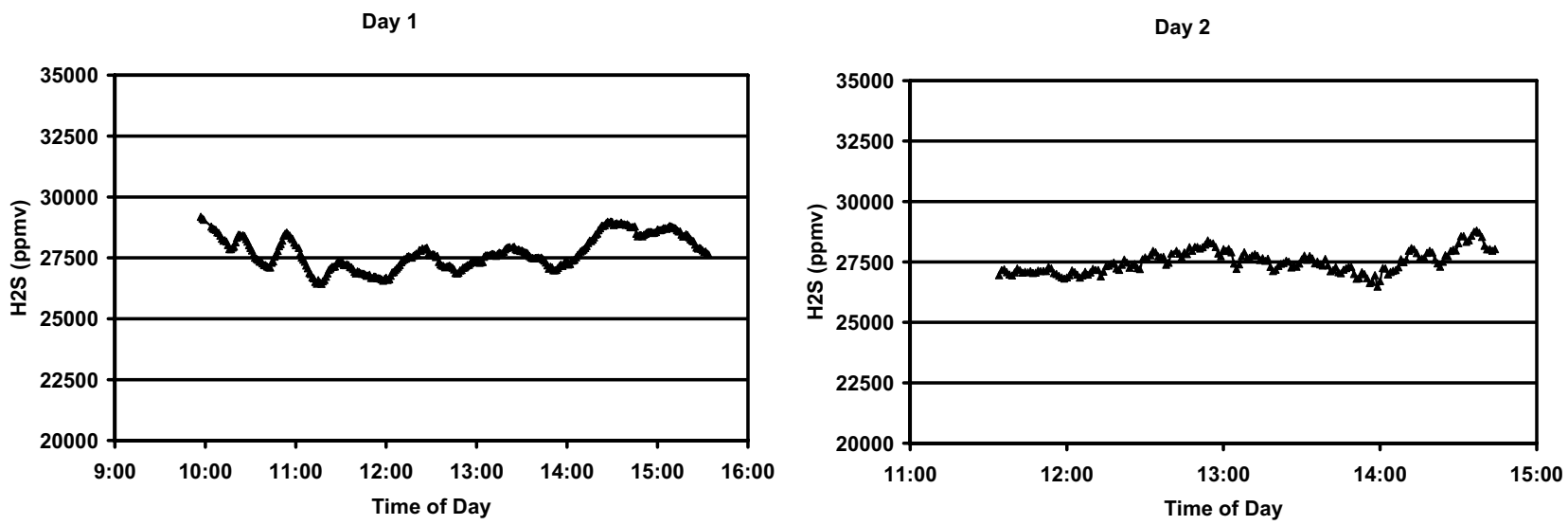

Figure $18 . \mathrm{H}_{2} \mathrm{~S}$ monitor stability runs.

Each data point in Figures 18 represents a 60 -second data integration. Periodic variations are noted in both plots. These variations are most likely due to etalon effects induced by the cell windows. As previously described, the reflection of the light from one surface of the flat window plates interferes with light reflected from the second surface, producing light and dark fringes. The laser signal used to detect absorption is then superimposed on the top of these fringes as seen in these figures. While etalon effects tend to average out over long periods of time, they clearly impact the measurement sensitivity for realtime process control. 
The results of a 24 hour-experiment are presented in Figure 19. For this experiment, the instrument was calibrated using a standard gas cylinder containing 53,500 $\pm 535 \mathrm{ppmv}_{2} \mathrm{~S}$ in nitrogen. Using this calibration, the instrument measured a concentration of $25,050 \mathrm{ppmv}$ in the vent stream. Shortly before this procedure, the NCPA chemist also collected a sample for analysis via the Tutwiler technique. His sample read 27,100 ppmv or about $8 \%$ higher than that obtained by the gas calibration. This was a reasonable correlation in view of the known errors associated with the two disparate measurements. The calibration gas was a primary grade quoted with a blend variance $\pm 5 \%$ and an analytical accuracy of $\pm 1 \%$. The spectroscopy instrument also introduces some errors in calibration in its ability to fit to the absorption peak, quoted by the manufacturer as $\pm 5 \%$.

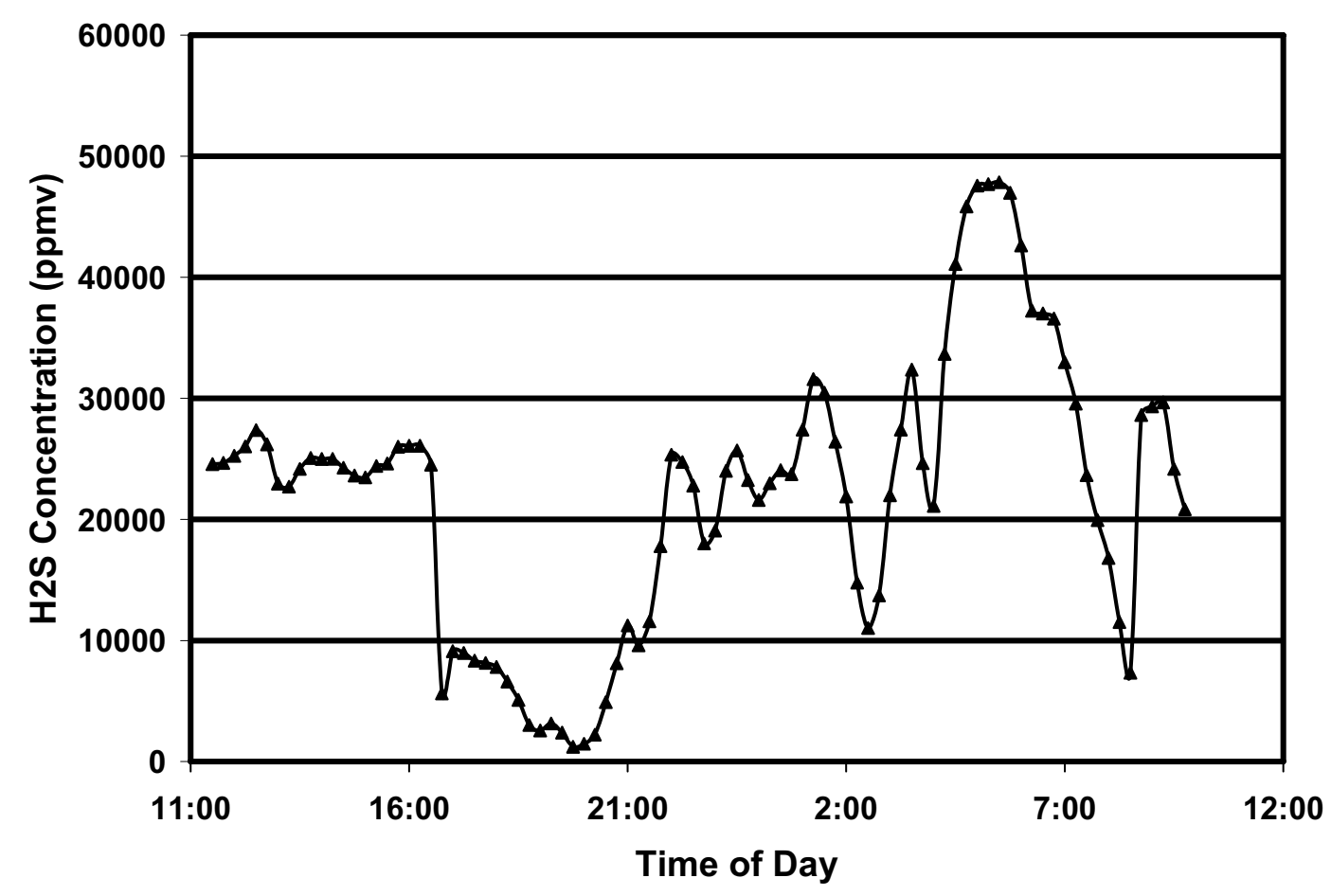

Figure 19. $\mathrm{H}_{2} \mathrm{~S}$ monitor overnight data collection from the untreated vent gas steam.

In reviewing the data from the overnight run, a reasonably stable operation was observed for the first 7 hours with the sensitivity limited only by the periodic etalon interferences. The NCPA chemist collected and analyzed another sample at approximately 1400 hours, reporting a stream calibration of 29,700 ppmv. The near-infrared spectroscopy system read only $24,773 \mathrm{ppmv}$ at this time. From the plot, this larger variance may be due to an etalon excursion that was occurring around that time.

Shortly after 1600 hours, there was a sharp drop in signal, which occurred after the investigators left the facility. Changes in the plant operation during this period could not account for this large a variation in the measurement and a change of this size could also not be attributed to the etalon interferences. It was speculated that the significant variations were due to condensation of water in the lines connecting the sample cell to the plant vent gas system piping. During the stability runs, condensed and entrained water collected in the filters on the inlet line. The rate of accumulation increased with colder air temperatures. Therefore, the low readings that occurred shortly after 1600 hours may have resulted from the collection of condensate in the flexible return line between the test cell and the low pressure vent gas system piping. (Flow and pressure were controlled with hand valves just upstream of 
the sample cell and just before the return gas entered the low pressure piping.) This flexible line contained several low spots where liquid could have collected, particularly since it had not been drained during previous test runs. The trapped moisture is suspected to have restricted the flow of gas through the sampling cell, raising its pressure and as seen in the laboratory experiments lowering the signal level. It appears that the liquid blockage or restriction in the outlet line cleared before midnight and the signal returned to the 20,000-30000 ppmv range.

Similarly, it is believed that the excursion that occurred during the early morning hours resulted from the accumulation of condensate in the supply line to the sampling cell. If flow were restricted due to condensate accumulation in the outlet line, then condensation could be expected to also occur in the supply line. If the moisture accumulated in the supply line to a level where it restricted flow, then the operating pressure of the cell would decrease. The effect of a lower pressure would be to increase sensitivity (see Figure 8), hence the higher signal.

Interestingly, when the NCPA chemist collected data at approximately 0930 hours, in spite of the large cycles in the signal recorded during the evening, the measurements again tracked to within $8 \%$. The Tutwiler method indicated $\mathrm{H}_{2} \mathrm{~S}$ was present at a level of 28,000 ppmv and the laser spectroscopy system indicated the level was 30,098 ppmv. A final sample collected at the conclusion of the test indicated a concentration of 29,000 ppmv with the Tutwiler method and 27,208 ppmv with the laser system.

The results of this initial test indicated that the instrument was able to be placed on-line in a geothermal plant process stream and be calibrated to within $8 \%$ of an independent measurement. The instrument exhibited good short (5-7 hr) operation with a typical precision of \pm 25 ppmv per meter, comparable to laboratory operation. Longer term stability was limited by two effects: signal modulation caused by etalon interferences and pressure variations caused by the build-up of condensate in the side stream tubing.

\subsection{On-line Measurement of $\mathrm{H}_{2} \mathrm{~S}$ in the Treated Vent Gas Stream}

\subsubsection{NCPA Unit 1 Short-term Deployment and Evaluation}

In order to address these issues, and to evaluate the system performance in a process stream containing a lower concentration of $\mathrm{H}_{2} \mathrm{~S}$, a second field test was conducted at NCPA Unit 1 using a side stream taken from the treated vent gas exciting the Stretford system. This process stream contained $\mathrm{H}_{2} \mathrm{~S}$ in a mixture of other gases with a concentration that varied from 0-20 ppmv. Two different sample cell configurations were evaluated for this work. The first was a $5-\mathrm{cm}$ diameter stainless steel tube, pictured in Figure 20 that could be varied in length from $0.1-10 \mathrm{~m}$ by adding or removing sections of tubing. The tube was operated with double pass geometry using the fiberoptically-coupled telescope and retroreflector assemblies, allowing for measurement path lengths up to $20 \mathrm{~m}$. The cell length and experimental configuration are similar to that of the cooling tower stack application. Anti-reflective coatings were applied to the windows to reduce etalon effects.

The second configuration, shown schematically in Figure 21, involved the use of a 15-cm diameter, 1.5 -m glass cell with two highly reflective mirrors. The mirrors are capable of being tilted relative to each other in such a way that the light can be reflected many times within the volume of the cell. This cell, obtained from Unisearch Associates (Ontario, Canada), can be varied in path length from 9 to $213 \mathrm{~m}$. 


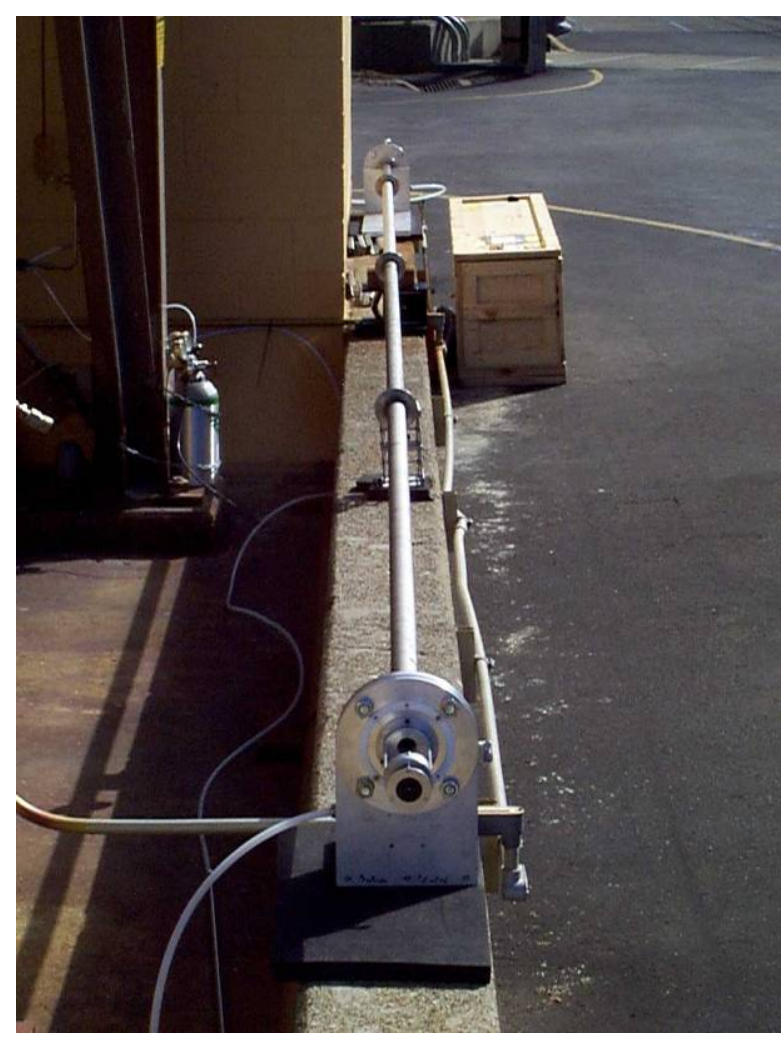

Figure 20. Picture of the double-pass sampling cell.

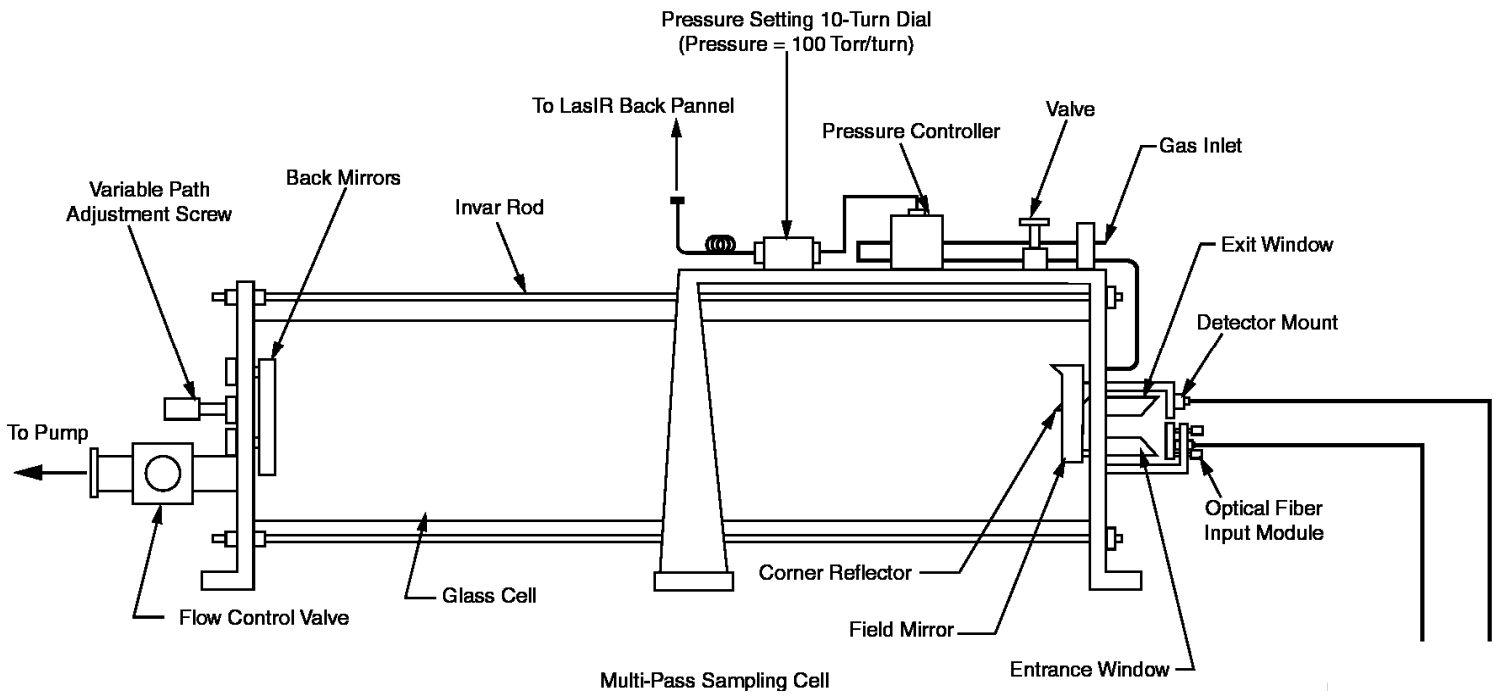

Figure 21. Multi-pass cell schematic.

There are trade-offs between the two cell types in size-footprint, sensitivity, and maintainability. The multi-pass cell occupies a smaller area and is capable of more sensitive measurements due to the longer path length. However, the tube geometry is easier to maintain. If the windows become contaminated they can easily be removed and washed using standard optical cleaning procedures. (These 
windows are also relatively inexpensive to replace.) The multi-pass cell, on the other hand, is far more susceptible to contamination since the beam is reflected many times using the same surfaces. In addition, the high reflectivity gold surface of the mirror is more difficult to clean without damaging and could require periodic refinishing to maintain performance. Both cells were tested in the laboratory using a certified gas mixture of $\mathrm{H}_{2} \mathrm{~S}$ in nitrogen at 10 ppmv levels. A plot of representative data from those experiments is presented in Figure 22. Both systems track the concentration at the same level; however, the 100-m measurement exhibits less variation in the signal, or better precision.

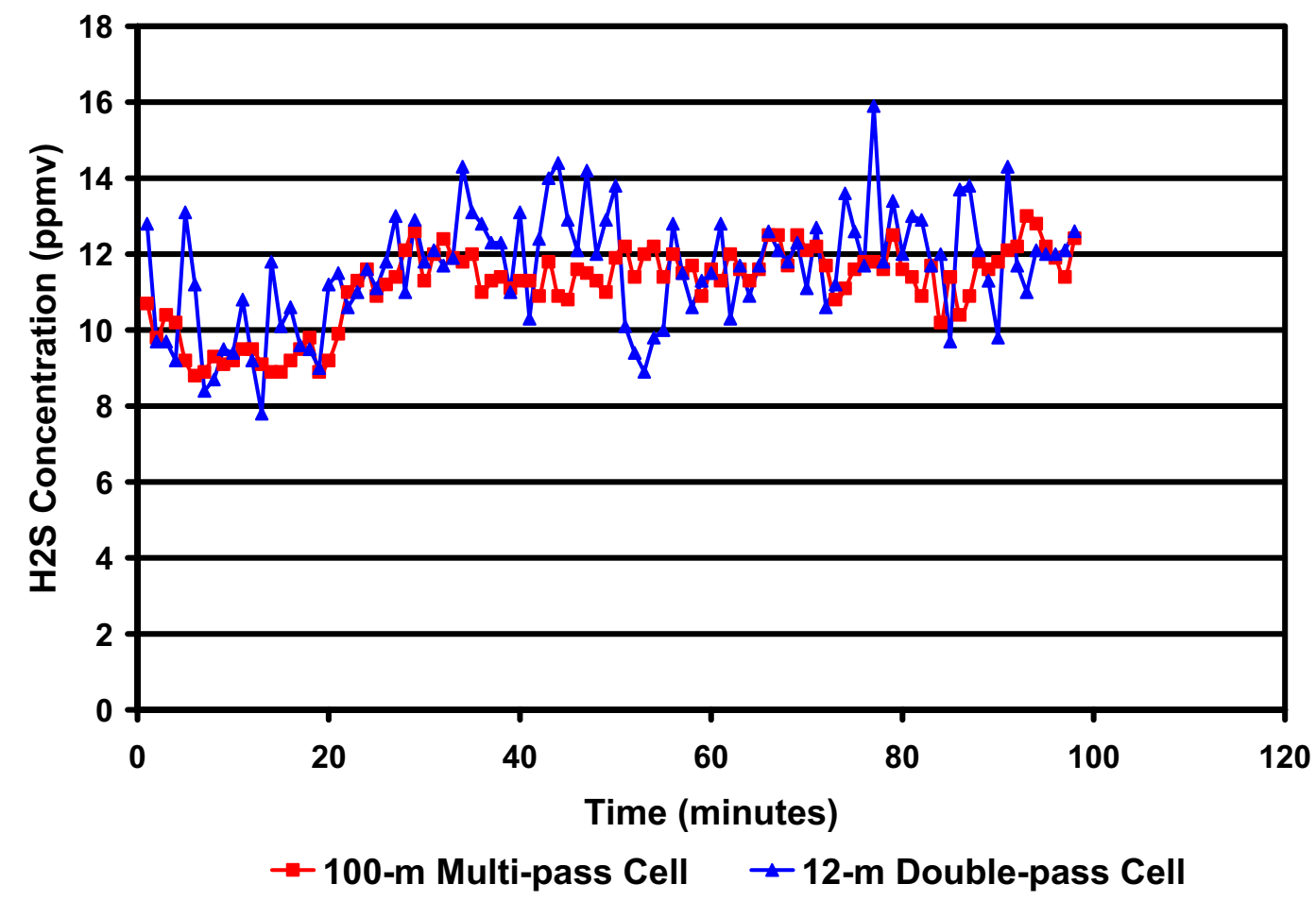

Figure 22. Comparison of 20-m double-pass tube cell and 100-m multi-pass White cell signals in response to $10-\mathrm{ppmv} \mathrm{H}_{2} \mathrm{~S}$ in nitrogen gas.

Both of these cells were installed and operated for periods of time during the field experiments at NCPA Unit 1. However, the multi-pass cell was used for the majority of testing since the treated vent gas stream tended to contain concentrations of $\mathrm{H}_{2} \mathrm{~S}$ in the low ppm range, placing it at the lower limits of detection with the shorter path length double-pass tube cell. For the initial assessment, a side stream was taken from the treated vent gas from the Unit Stretford system as illustrated in Figure 23. The stream was controlled to a pressure of around $0.1 \mathrm{~atm}$ and introduced into the multi-pass cell at a flow rate of approximately 1.5 standard liters per minute. The multi-pass cell was adjusted to a path length of 90 meters and the system was calibrated with 10-ppmv $\mathrm{H}_{2} \mathrm{~S}$ in nitrogen supplied from a certified calibration gas cylinder. The system was placed on-line with the Houston Atlas system, which senses a color change in a lead-acetate tape in response to $\mathrm{H}_{2} \mathrm{~S}$ concentration. (The multi-pass system is shown deployed next to this system in Figure 24.) 

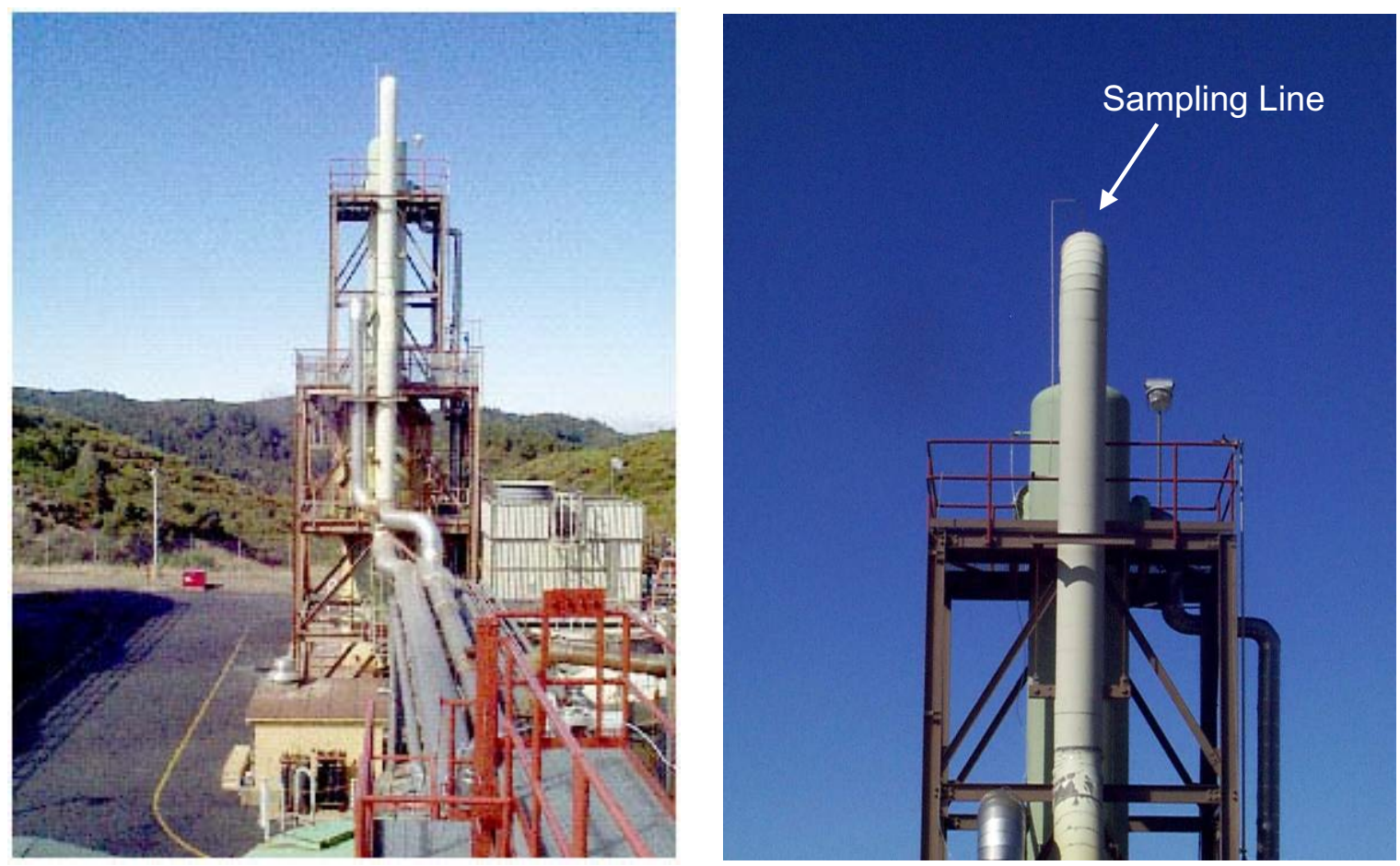

Figure 23. Overview and close-up images of treated vent gas stream sampling location.

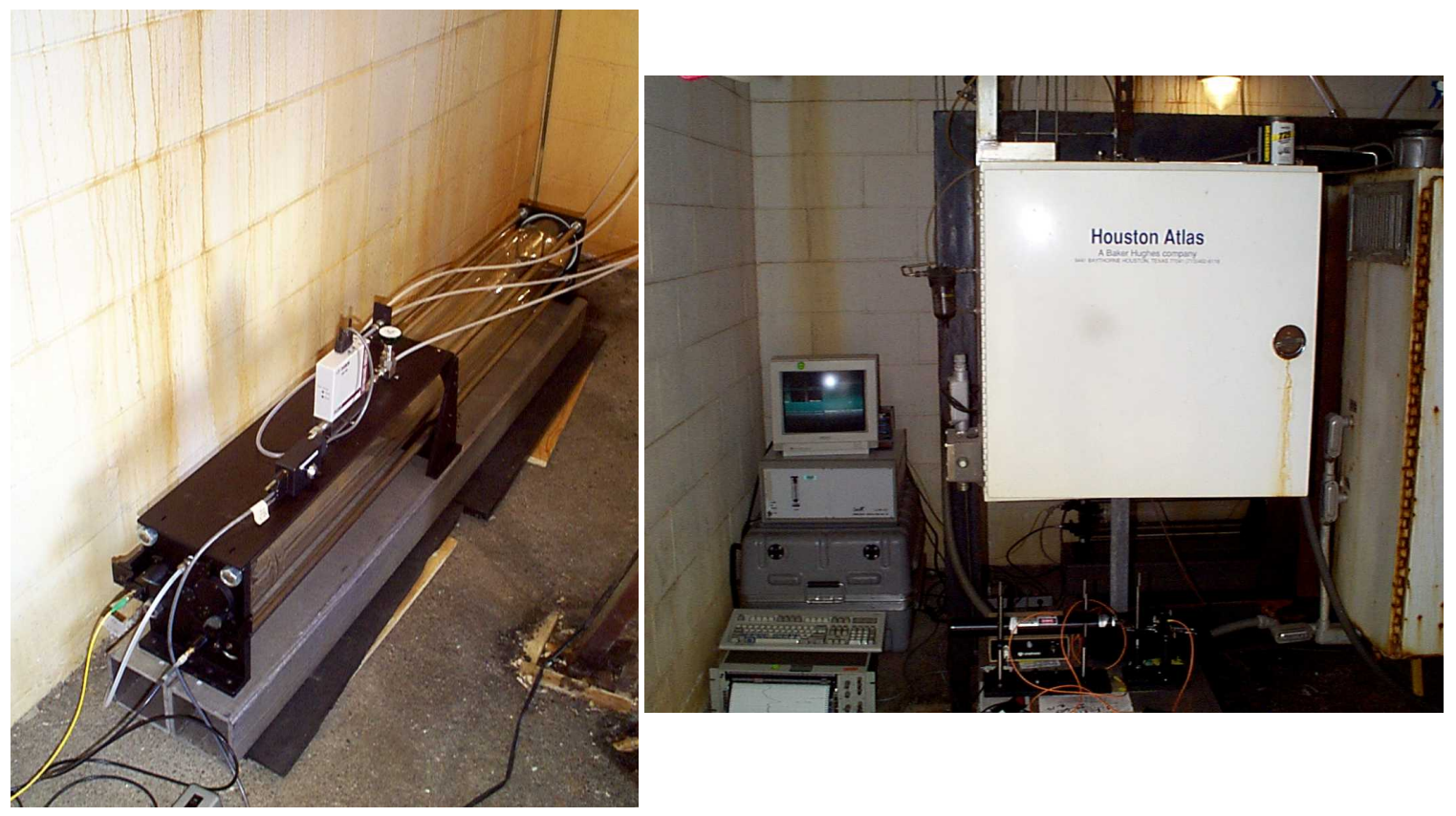

Figure 24. Multi-pass cell (left) and near-infrared spectroscopy instrumentation (right) deployed behind Houston Atlas system at NCPA Unit 1.

The data collected over a $3 \frac{1}{2}$ day operation of the instrument at NCPA Unit 1 is presented in Figure 25. As illustrated, the system was periodically calibrated using gas from a certified cylinder containing 10-ppmv $\mathrm{H}_{2} \mathrm{~S}$ in nitrogen. The system exhibited good stability over this time period with a typical precision of $\pm 50 \mathrm{ppbv}$. It was also able to track process changes in agreement with independent 
measurements made by the Houston Atlas system, but with an off-set in the actual value. This may be due to differences in calibration between the devices. (The Houston Atlas is calibrated at 300 ppmv but the calibration is only good to $\pm 10 \%$ of range.) Unlike the previous testing, the system exhibited minimal operational problems from condensate build-up, pressure and flow variations, or optical etalons.

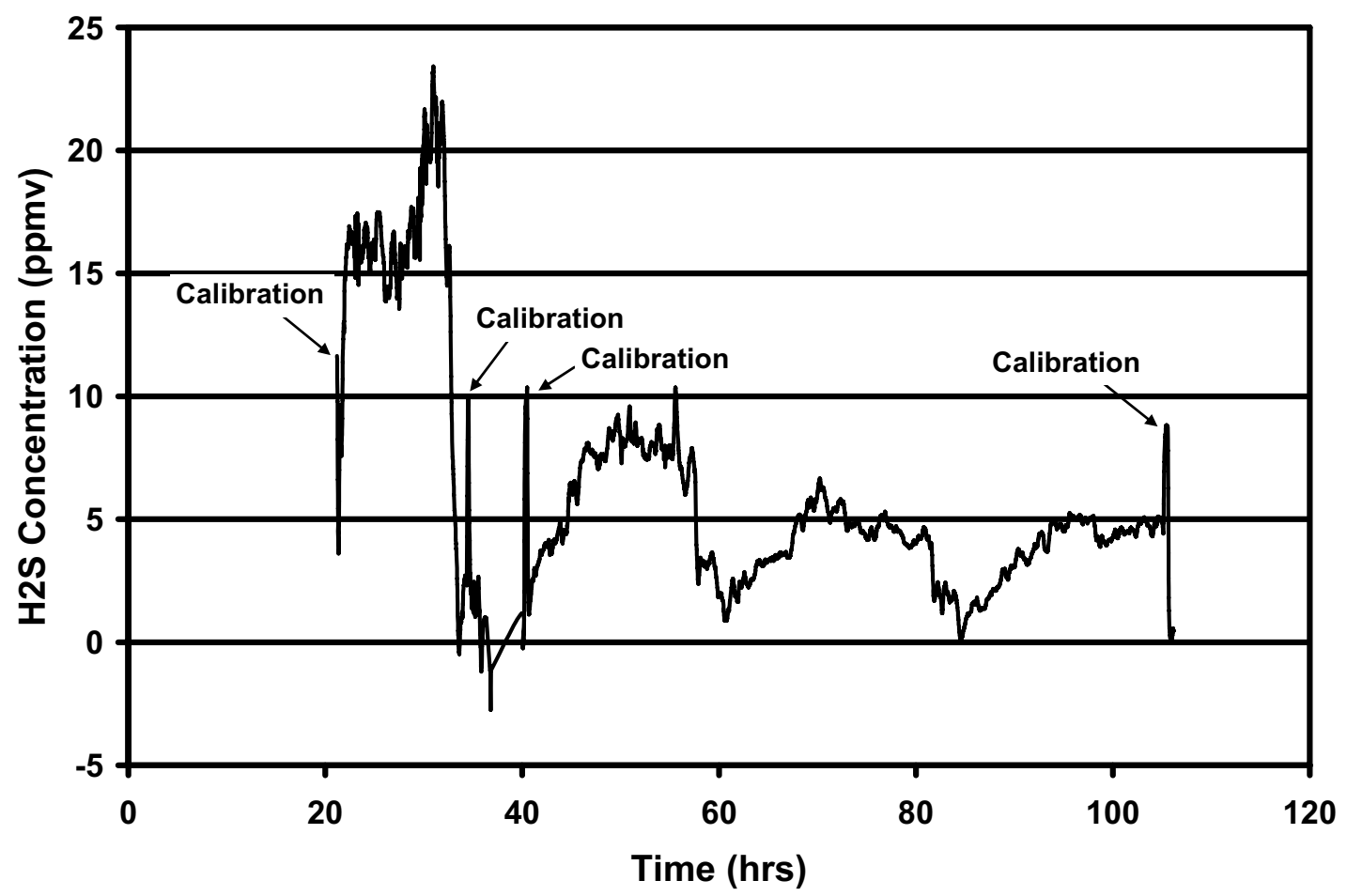

Figure 25. $3 \frac{1}{2}$ day $\mathrm{H}_{2} \mathrm{~S}$ monitor operation in NCPA Unit 1 treated vent gas stream.

\subsubsection{NCPA Unit 2 Extended Deployment and Evaluation}

The $\mathrm{H}_{2} \mathrm{~S}$ monitor was deployed at NCPA Unit 2 for an extended field trial. The goal of this effort was to determine the long-term stability and maintainability of the instrument under field conditions. The $100-\mathrm{m}$, multi-pass cell was again used to sample a slip stream from the treated vent gas stream exiting the Stretford system. The stream was controlled to a pressure of around $0.1 \mathrm{~atm}$ and introduced into the multipass cell at a flow rate of around 1.5 standard liters per minute. The experimental set up at the facility is shown in Figures 26-27. The instrumentation was located inside the Stretford control room. The laser probe signal was transmitted to the multi-pass cell over an optical fiber and detected at the cell output with a germanium detector. The detector response and control signals for the automated calibration unit were transmitted over coaxial cables. During the extended deployment, the instrument successfully collected data for periods up to eight weeks with no operator intervention. The readings tracked with the $\mathrm{H}_{2} \mathrm{~S}$ levels measured with the plant's Houston Atlas instrument within the known uncertainties of the two devices, employing an automated calibration system that periodically introduced a certified sample from a gas cylinder. No significant contamination or deterioration of the multi-pass cell mirrors was observed.

The data collected during the eight week run is presented in Figure 28. The data plotted is averaged over a three minute interval. The spikes near concentrations of $10 \mathrm{ppmv}$ are due to the introduction of the calibration gas. 


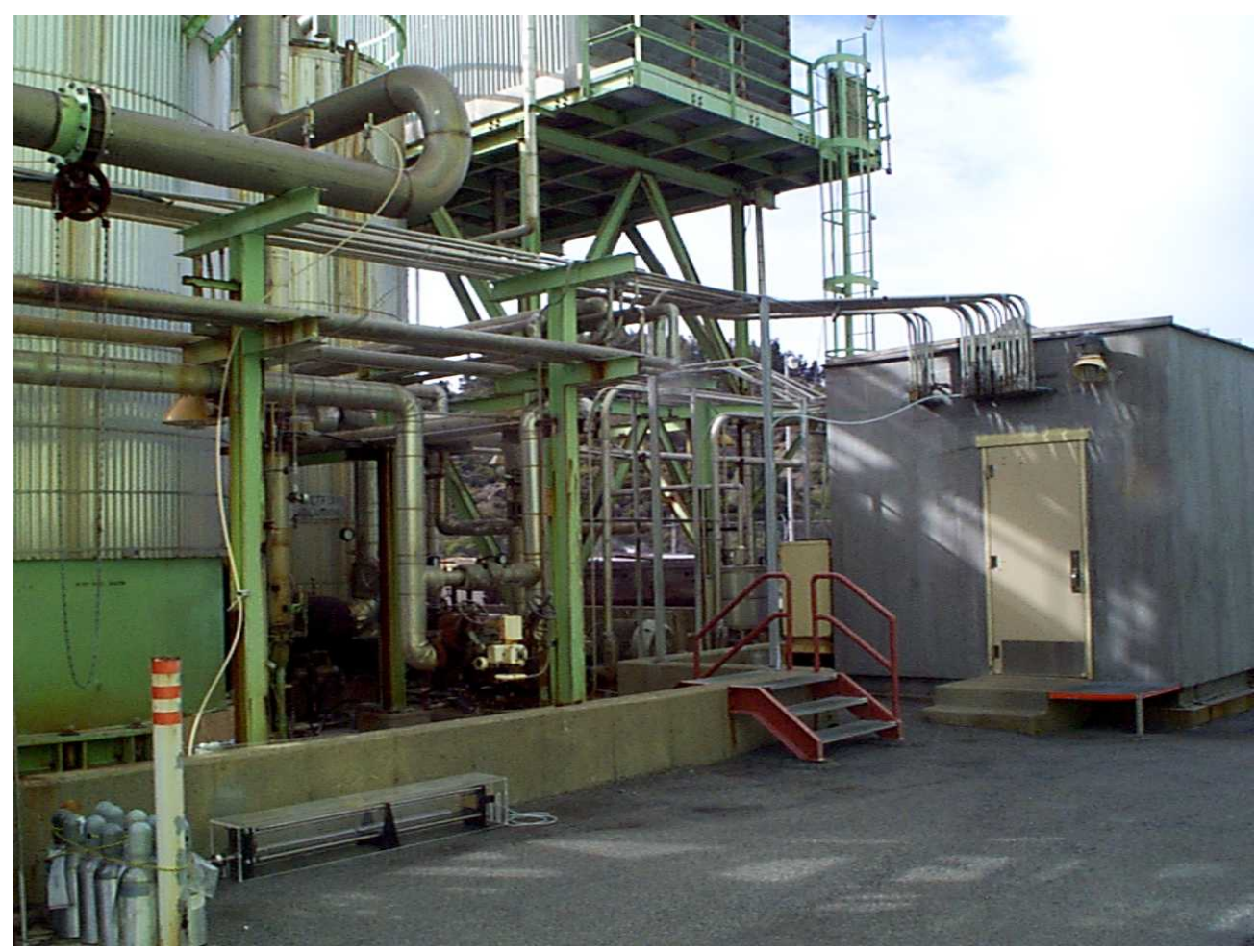

Figure 26. Stretford control room at NCPA Unit 2.
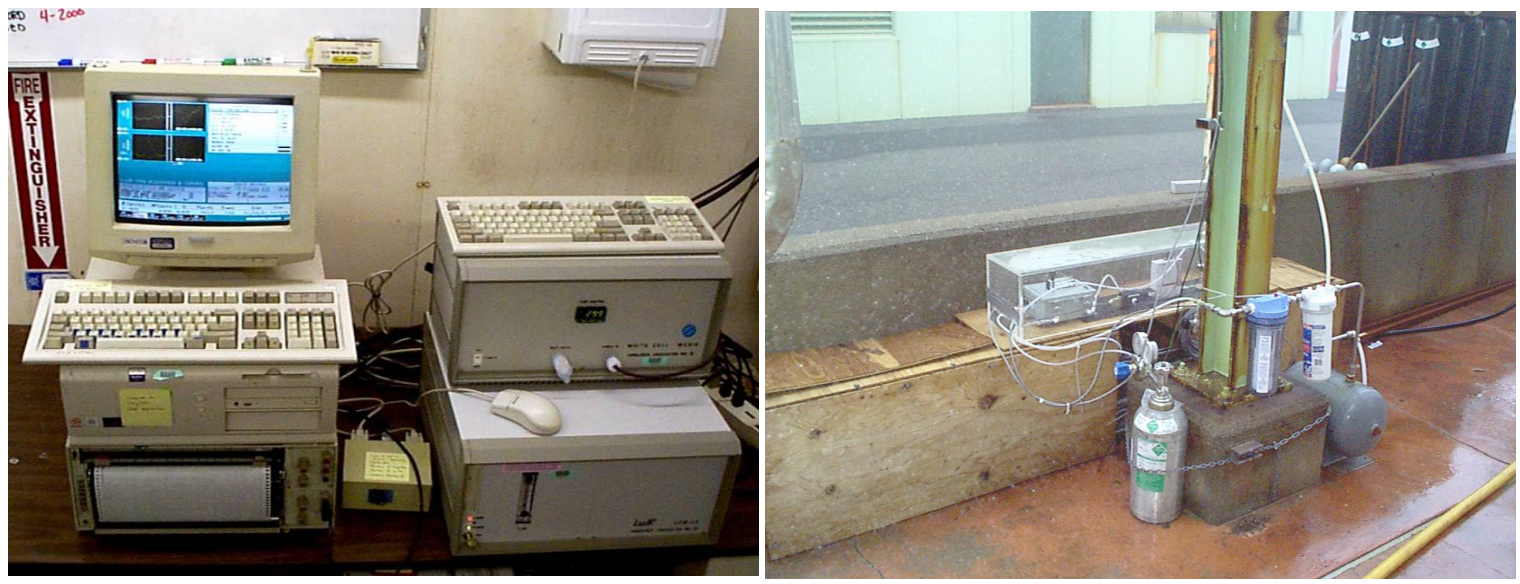

Figure 27. Fiber-coupled spectroscopy instrumentation (left) located in the control room. Multi-pass cell and auto-calibration hardware (right) housed in boxes outside. 


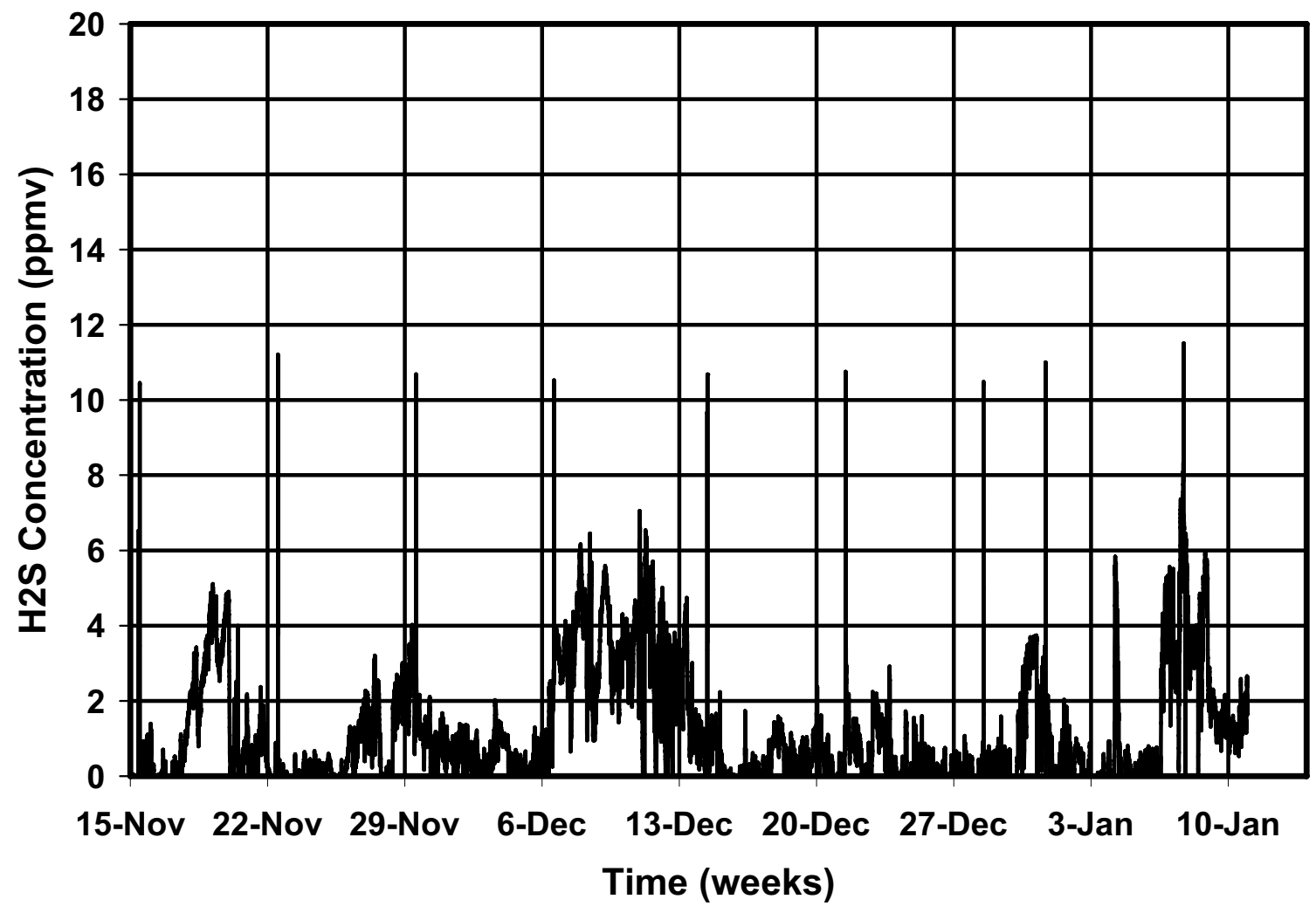

Figure 28. $\mathrm{H}_{2} \mathrm{~S}$ concentration collected on-line in the treated vent gas stream using the multi-pass cell and automatic calibration unit. 


\section{CONCLUSIONS}

The application of a near-infrared, tunable laser spectroscopy has been investigated for the realtime monitoring of gas species in geothermal power production facilities. The investigation concluded that the technology could be successfully used to collect real-time data in some process streams, such the vent gas stream. The device was also able to operate, using an automated calibration system, with minimal support from the plant operators over a two-month evaluation period. However, the instrument was not sensitive enough to make measurements in the cooling stack or steam line applications where the required detection limits are in the 0.1 to 5 -ppbv range. The principle limitation was that the infrared absorption bands that could be measured with near-infrared diodes were not sufficiently absorptive to conduct ppbv measurements without resorting to the use of very long optical measurement paths. (The use of long measurement paths is not practical for many applications since the probe beam may be attenuated to unusable levels by droplet or other scattering phenomena.) In addition, at atmospheric and elevated pressures there was spectral interference from other species such as water vapor and carbon dioxide.

In recent years, a new type of high-intensity laser has been developed that can be used to perform low-noise, tunable spectroscopy. ${ }^{16-17}$ In contrast to semiconductor devices, the laser transitions in the new quantum cascade laser technology occur between quantized energy levels in a series of coupled quantum wells with the conduction band. Because the transition energy is primarily determined by quantum confinement, different transition energies can be realized by adjusting individual layer thicknesses instead of changing the composition of the constituent material. This technique, called band structure engineering, allows the device to emit radiation over a wide range of infrared frequencies. ${ }^{18}$ Consequently, these devices can be designed to operate at longer wavelengths where the absorption bands of the species of interest are much stronger and there is more isolation from interfering species. ${ }^{19}$ The integration of these devices into robust instruments for geothermal plant process monitoring applications could allow realtime measurements to be performed in more locations at the plants. 


\section{REFERENCES}

1. Assessment of $\mathrm{H}_{2} \mathrm{~S}$ Control Technologies for Geothermal Power Plants, Acurex Corporation, Contract No. 300-031, California Energy Commission, Sacramento, CA, February 1980.

2. Gary J. Nagel, "Controlling $\mathrm{H}_{2} \mathrm{~S}$ Emissions In Geothermal Power Plants," Energy-Tech On-line, ee0002_004, 2002.

3. Michael D. Rogers, "Design, Construction and Operation of Geysers Unit 18," Monograph on The Geysers Geothermal Field, Geothermal Resources Council, Davis, CA, 1992, pp. 317-324.

4. A. H. Truesdell, J. H. Haizlip, H. Armannsson, and F. D'Amore, "Origin and Transport of Chloride in Superheated Geothermal,” Geothermics, Vol. 18, 1989, pp. 295-304.

5. D. W. Fisher and D. B. Jung, "Alternatives to Traditional Water Washing Used to Remove Impurities in Superheated Geothermal Steam," Geothermal Resources Council Transactions, Vol. 20, 1996, pp. 737-741.

6. D. E. Cooper and R. U. Martinelli, "Near-Infrared Diode Lasers Monitor Molecular Species," Laser Focus World, Vol. 38, 1992, pp. 133-146.

7. P. Werle, R. Mürke, F. D. Amato, and T. Lancia, "Near-Infrared Trace-Gas Sensors based RoomTemperature Diode Lasers," Appl. Phys. B, Vol. 67, pp. 307-315.

8. M. P. Arroyo and R. K. Hanson, “Absorption Measurements of Water-Vapor Concentration, Temperature, and Line-Shape, Parameters Using a Tunable InGaAsP Diode Laser," App. Opt., Vol. 21, 1993, pp. 6104-6116.

9. Alan Fried, Dennis K. Killinger, and Harold Schiff, (Editors), Tunable Diode Laser Spectroscopy, Lidar, and DIAL Techniques for Environmental and Industrial Measurements, SPIE, Vol. 2112, 1993.

10. J. K. Partin and C. L. Jeffery, "Investigation of Near-Infrared Diode Laser Spectroscopy for $\mathrm{H}_{2} \mathrm{~S}$ Monitoring in Geothermal Plants," Geothermal Resources Council Transactions, Vol. 22, 1998, pp. 435-439.

11. H. Riris, et al., "Frequency Modulation Spectroscopy with Tunable Diode Lasers," SPIE, Vol. 2112 , pp. 12-18.

12. J. A. Silver, "Frequency Modulation Spectroscopy for Trace Species Detection: Theory and Comparison Among Experimental Methods," Appl. Opt., Vol. 31, 1992, pp. 707-717.

13. G. R. Janik, C. B. Carlisle, and T. F. Gallagher, "Two-tone Frequency Modulated Spectroscopy," J. Opt. Soc. Am. B, Vol. 3, 1986, pp. 1070-1074.

14. H. Lotem, "Extension of the Spectral Coverage Range of Frequency Modulation Spectroscopy by Double Frequency Modulation,” J. App. Phys., Vol. 54, 1983, pp. 6033-6035.

15. A. N. Dharamsi and A. M. Bullock, "Applications of Wavelength-Modulation Spectroscopy in Resolution of Pressure and Modulation Broadened Spectra," Appl. Phys. B, Vol. 63, 1996, pp. 283-292. 
16. F. Capasso, et al., "Quantum Cascade Lasers," Science, Vol. 264, 1994, pp. 553-555

17. F. Capasso, et al., "High Performance Quantum Cascade Lasers," Optics and Photonics News, Vol. 10, 1999, pp. 31-37.

18. F. Cappasso, "Band Gap Engineering: from Physics and Materials to New Semiconductor Devices," Science, Vol. 235, 1987, pp. 172-176.

19. C. Mann, et al., "Quantum Cascade Lasers for the Mid-infrared Spectral Range: Devices and Applications," Advances in Solid State Physics, Vol. 43, 2003, pp. 351-368. 